\title{
Dihydrofolate Reductase Inhibitors: The Pharmacophore as a Guide for Co-Crystal Screening
}

\author{
João A. Baptista ${ }^{1}$, Mário T. S. Rosado ${ }^{1}{ }^{(0}$, Ricardo A. E. Castro ${ }^{1,2}{ }^{\circledR}$, António O. L. Évora ${ }^{1,3}$, Teresa M. R. Maria ${ }^{1}$, \\ Manuela Ramos Silva ${ }^{4}$, João Canotilho ${ }^{1,2}$ and M. Ermelinda S. Eusébio ${ }^{1, *(D)}$ \\ 1 CQC, Departamento de Química, Universidade de Coimbra,3004-535 Coimbra, Portugal; \\ jabaptista@qui.uc.pt (J.A.B.); mario.rosado@qui.uc.pt (M.T.S.R.); rcastro@ff.uc.pt (R.A.E.C.); \\ antonio.evora@uc.pt (A.O.L.É.); troseiro@ci.uc.pt (T.M.R.M.); jcano@ci.uc.pt (J.C.) \\ 2 Faculdade de Farmácia, Universidade de Coimbra,3000-548 Coimbra, Portugal \\ 3 Ctr Quim Estrutural, Faculdade Ciências, Universidade de Lisboa,1749-016 Lisboa, Portugal \\ 4 CfisUC, Departmento de Física, Universidade de Coimbra, 3004-535 Coimbra, Portugal; manuela@fis.uc.pt \\ * Correspondence: quierme@ci.uc.pt; Tel.: +351-239854450
}

\section{check for} updates

Citation: Baptista, J.A.; Rosado, M.T.S.; Castro, R.A.E.; Évora, A.O.L.; Maria, T.M.R.; Ramos Silva, M.; Canotilho, J.; Eusébio, M.E.S. Dihydrofolate Reductase Inhibitors The Pharmacophore as a Guide for Co-Crystal Screening. Molecules 2021, 26, 6721. https://doi.org/10.3390/ molecules26216721

Academic Editor: Carlos Eduardo Sabino Bernardes

Received: 4 October 2021

Accepted: 2 November 2021

Published: 6 November 2021

Publisher's Note: MDPI stays neutral with regard to jurisdictional claims in published maps and institutional affiliations.

Copyright: (c) 2021 by the authors. Licensee MDPI, Basel, Switzerland. This article is an open access article distributed under the terms and conditions of the Creative Commons Attribution (CC BY) license (https:// creativecommons.org/licenses/by/ $4.0 /)$.
Abstract: In this work, co-crystal screening was carried out for two important dihydrofolate reductase (DHFR) inhibitors, trimethoprim (TMP) and pyrimethamine (PMA), and for 2,4-diaminopyrimidine (DAP), which is the pharmacophore of these active pharmaceutical ingredients (API). The isomeric pyridinecarboxamides and two xanthines, theophylline (THEO) and caffeine (CAF), were used as co-formers in the same experimental conditions, in order to evaluate the potential for the pharmacophore to be used as a guide in the screening process. In silico co-crystal screening was carried out using BIOVIA COSMOquick and experimental screening was performed by mechanochemistry and supported by (solid + liquid) binary phase diagrams, infrared spectroscopy (FTIR) and X-ray powder diffraction (XRPD). The in silico prediction of low propensities for DAP, TMP and PMA to co-crystallize with pyridinecarboxamides was confirmed: a successful outcome was only observed for DAP + nicotinamide. Successful synthesis of multicomponent solid forms was achieved for all three target molecules with theophylline, with DAP co-crystals revealing a greater variety of stoichiometries. The crystalline structures of a (1:2) TMP:THEO co-crystal and of a (1:2:1) DAP:THEO:ethyl acetate solvate were solved. This work demonstrated the possible use of the pharmacophore of DHFR inhibitors as a guide for co-crystal screening, recognizing some similar trends in the outcome of association in the solid state and in the molecular aggregation in the co-crystals, characterized by the same supramolecular synthons.

Keywords: co-crystal screening; dihydrofolate reductase inhibitors; pharmacophore; trimethoprim; pyrimethamine; 2,4-diaminopyrimidine; pyridinecarboxamides; theophylline; caffeine

\section{Introduction}

Dihydrofolate reductase (DHFR) inhibitors are commonly used as a first-line therapy for diseases such as malaria, tuberculosis and toxoplasmosis [1-7]. They have also been used, for instance, in cancer therapy [3,8-10] and have been investigated as inhibitors of Bacillus anthracis, the agent responsible for anthrax [11]. Most DHFR inhibitors share a common 2,4-diaminopyrimidine (DAP) scaffold (Figure 1a.), such as in trimethoprim (TMP) (Figure 1b) and in pyrimethamine (PMA) (Figure 1c), which has been found to play an important role in interactions with the target enzyme $[1,2,4,7]$.

Co-crystals have emerged in recent years as attractive, alternative solid forms of active pharmaceutical ingredients (APIs), with several studies aiming at the optimization of their physicochemical properties and/or biopharmaceutical performance [12]. They are made up of the API and of one or more co-formers, all of which are solids when pure and at ambient conditions, joined together in a stoichiometric ratio in a new crystalline structure [12,13]. 
The co-crystal components are associated in supramolecular synthons, most commonly linked by hydrogen bond interactions [12,13].

The supramolecular synthon approach, which looks for hydrogen bonding complementarities between the target molecule and the potential co-formers, is often used as a starting point for co-crystal screening $[14,15]$. In this context, it is interesting to investigate if DAP can be a guide for the screening of co-crystals of DHFR inhibitors containing this pharmacophore: the same type of supramolecular synthons is expected for DAP and for the DHFR inhibitors, although the molecular complexity of the latter may also play a role in the co-crystallization trial outcome. Although several studies can be found in literature concerning the investigation of co-crystals, and mainly of salts of TMP [16-25] and PMA [19,26-34] and, to a lesser extent, of DAP [35-39], to the best of our knowledge, an investigation comparing co-crystallization of these three related compounds with the same potential co-formers is not available.

The current work presents the results of an ongoing investigation of co-crystallization of trimethoprim, pyrimethamine and the core fragment 2,4-diaminopyrimide with different co-formers. Experimental results of co-crystallization screening, carried out in the same experimental conditions, are presented and discussed for DAP and TMP with two different types of co-formers that are capable of giving rise to different supramolecular heterosynthons, with the target molecules having, therefore, different competing/complementary effects towards the target homodimers: the three isomeric pyridinecarboxamides, picolinamide (PA), nicotinamide (NA) and isonicotinamide (INA), and the two xanthines, theophylline (THEO) and caffeine (CAF) (Figure 1). Some possible hydrogen-bonded motifs between the DAP scaffold and each of these types of co-formers are shown in Figure $1 \mathrm{i}$ and 1.j. The screening of co-crystals between PMA and the pyridinecarboxamides is also carried out, complementing our previous work [27] on the co-crystallization of this DHFR inhibitor with caffeine and theophylline.

(a)<smiles>Nc1ccnc(N)n1</smiles>

(d)<smiles>NC(=O)c1ccccn1</smiles>

(i)

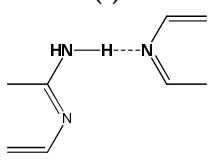

(b)<smiles>COc1cc(Cc2cnc(N)nc2N)cc(OC)c1OC</smiles>

(e)<smiles>NC(=O)c1cccnc1</smiles><smiles>C=CN(NC(C)=O)[NH+](C=C)CC</smiles>

(j)

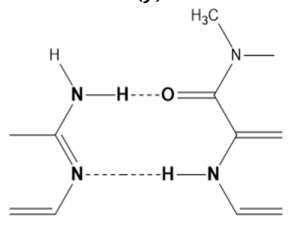

(c)<smiles>CCc1nc(N)nc(N)c1-c1ccc(Cl)cc1</smiles>

(f)<smiles>NC(=O)c1ccncc1</smiles>

(g)<smiles>Cn1c(=O)c2[nH]cnc2n(C)c1=O</smiles><smiles>Cn1c(=O)c2c(ncn2C)n(C)c1=O</smiles>

(h)

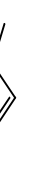<smiles>C=CN1CNC(C)=C(C)NC1</smiles> 


\section{Results and Discussion}

COSMOquick software $[40,41]$ was used in the search for the propensity of DAP, TMP and PMA to form co-crystals with the co-formers that are investigated in the current work. This approach takes into account the interaction between the target compound and the coformer as the excess enthalpy $\left(\Delta H_{\mathrm{ex}}\right)$ of the undercooled melt made up of both components in a specified proportion [41]. The software also calculates the empirical parameter $f_{\text {fit }}$ for a 1:1 stoichiometry which, in addition to $\Delta H_{\mathrm{ex}}$, also takes into account the flexibility of the molecules described by the number of rotatable bonds of the target molecule and the co-former [41]. Negative $\Delta H_{\text {ex }}$ values and low $f_{\text {fit }}$ values should indicate a propensity for co-crystal formation.

Our previous results concerning PMA + THEO and PMA + CAF confirm successful (1:1) co-crystal formation for both systems, with polymorphism of the co-crystals being observed in both cases [27].

The results obtained for the systems that were investigated in the current work are presented in Table 1 and can provide a qualitative guide to the expectation of co-crystal formation. A general comparison of the estimated values for excess enthalpy of mixing indicate that a successful outcome is probable between DAP, TMP or PMA and the two investigated xanthines, although outcomes are less favorable for TMP. The estimated $\Delta H_{\mathrm{ex}}$ values with the pyridinecarboxamide co-formers show a more favorable tendency for the co-crystallization of these three molecules with DAP and picolinamide with PMA. Other values are close to zero and are probably not meaningful, while indicating a smaller likelihood of the co-crystallization of TMP with the three pyridinecarboxamides.

Table 1. COSMOquick parameters, $\Delta H_{\mathrm{ex}}\left(\mathrm{kcal} \mathrm{mol}^{-1}\right)$ and $f_{\text {fit }}$, obtained for co-crystal screening between the target compounds 2,4-diaminopyrimidine, trimethoprim and pyrimethamine, and the co-formers, picolinamide, isonicotinamide, nicotinamide, theophylline and caffeine; $x$ is the target compound mole fraction.

\begin{tabular}{|c|c|c|c|c|c|c|c|c|c|c|c|c|}
\hline & $\begin{array}{c}f_{\text {fit }} \\
x=0.50\end{array}$ & $\begin{array}{c}\Delta H_{\mathrm{ex}} \\
x=0.33\end{array}$ & $\begin{array}{c}\Delta H_{\mathrm{ex}} \\
x=0.50\end{array}$ & $\begin{array}{c}\Delta H_{\mathrm{ex}} \\
x=0.67\end{array}$ & $\begin{array}{c}f_{\mathrm{fit}} \\
x=0.50\end{array}$ & $\begin{array}{c}\Delta H_{\mathrm{ex}} \\
x=0.33\end{array}$ & $\begin{array}{c}\Delta H_{\mathrm{ex}} \\
x=0.5\end{array}$ & $\begin{array}{c}\Delta H_{\mathrm{ex}} \\
x=0.67\end{array}$ & $\begin{array}{c}f_{\mathrm{fit}} \\
x=0.50\end{array}$ & $\begin{array}{c}\Delta H_{\mathrm{ex}} \\
x=0.33\end{array}$ & $\begin{array}{c}\Delta H_{\mathrm{ex}} \\
x=0.5\end{array}$ & $\begin{array}{c}\Delta H_{\mathrm{ex}} \\
x=0.67\end{array}$ \\
\hline & \multicolumn{4}{|c|}{ Picolinamide } & \multicolumn{4}{|c|}{ Isonicotinamide } & \multicolumn{4}{|c|}{ Nicotinamide } \\
\hline DAP & 1.9 & -0.14 & -0.15 & -0.12 & 1.9 & -0.15 & -0.16 & -0.14 & 1.9 & -0.13 & -0.14 & -0.12 \\
\hline TMP & 4.6 & 0.02 & 0.02 & 0.02 & 4.6 & 0.04 & 0.04 & 0.03 & 4.6 & 0.05 & 0.04 & 0.03 \\
\hline PMA & 3.0 & -0.14 & -0.15 & -0.12 & 3.0 & -0.06 & -0.06 & -0.05 & 3.0 & -0.04 & -0.04 & -0.03 \\
\hline \multicolumn{5}{|c|}{ Theophylline } & \multicolumn{4}{|c|}{ Caffeine } & & & & \\
\hline DAP & 1.1 & -0.46 & -0.54 & -0.49 & 1.0 & -0.50 & -0.62 & -0.60 & & & & \\
\hline $\mathrm{TMP}$ & 3.9 & -0.26 & -0.28 & -0.25 & 4.0 & -0.14 & -0.16 & -0.14 & & & & \\
\hline PMA & 2.2 & -0.44 & -0.50 & -0.44 & 2.0 & -0.60 & -0.70 & -0.60 & & & & \\
\hline
\end{tabular}

\section{1. (DAP/TMP/PMA) + Pyridinecarboxamides Binary Systems}

Co-crystal formation of DAP, TMP and PMA with the isomeric pyridinecarboxamides was investigated experimentally using mechanochemistry as the screening method. Sample characterization was carried out using differential scanning calorimetry (DSC) together with the predicted (solid + liquid) binary phase diagrams, complemented by infrared spectroscopy (FTIR) or/and X-ray powder diffraction (XRPD) analysis.

Equation (1) was used to predict the liquidus for the binary systems made up of TMP or PMA and one of the pyridinecarboxamides and for DAP + PA and DAP + INA. Equations (1) and (2) [42] were used for DAP + NA system.

$$
\begin{gathered}
\frac{1}{T_{f u s}}=\frac{1}{T_{f u s}^{*}}-\frac{R \ln x_{i}}{\Delta_{f u s} H_{m}^{*}} \\
\frac{1}{T_{f u s}}=\frac{1}{T_{f u s}^{c c}}-\frac{R}{\Delta_{f u s} H_{m}^{c c}}\left\{\ln \left[x_{c c}\left(1-x_{c c}\right)^{3}\right]-\ln \left[x_{i}\left(1-x_{i}\right)^{3}\right]\right\}
\end{gathered}
$$

In these equations, $T_{\text {fus }}$ represents the liquidus temperature of a mixture of mole fraction $x_{\mathrm{i}} . T_{f u s}^{*}$ and $\Delta_{f u s} H_{m}^{*}$ are the melting temperature and molar melting enthalpy of 
the pure compound $i$; $T_{f u s}^{c c}$ and $\Delta_{f u s} H_{m}^{c c}$ are the corresponding values for the co-crystal. The melting temperature and enthalpy values presented in Table S1 (ESI) were used in the calculations. The experimental solidus was obtained from the onset of the first observed DSC peak and the liquidus from the corrected maximum of the second one [43,44].

For all the systems, except for DAP + NA, the binary (solid + liquid) phase diagrams (Figure S1; obtained from the DSC curves presented in Figures S2-S10) show only slight deviations from the predictions of a diagram with a simple eutectic, with the ideal liquid phase (eq. (1)) confirming that no co-crystals were obtained in the experimental conditions used. The infrared spectra shown as electronic supplementary material are, as expected, the sum of those of the target compound and of one of the polymorphs of the co-former (Figures S11 and S12-FTIR, DAP + PA and DAP + INA; Figures S13-S15FTIR, TMP + PA, TMP + INA and TMP + NA; Figures S16-S18-FTIR and PMA + PA, PMA + INA, PMA + NA).

A (1:3) DAP:NA co-crystal was synthesized by mechanochemistry, as confirmed by the experimental binary (solid + liquid) phase diagram shown in Figure 2, and by XRP (Figure 3) and FTIR (Figure S19). The binary (solid + liquid) phase diagram is quite well described by eq. (1) when an excess of DAP is present, and by eq. (2) in the vicinity of the co-crystal, between the two eutectic invariants at $T_{\mathrm{e} 1} \approx 124.5^{\circ} \mathrm{C}, x_{\mathrm{e} 1} \approx 0.04$ and $T_{\mathrm{e} 2} \approx 117.5^{\circ} \mathrm{C}, x_{\mathrm{e} 2} \approx 0.65$. Unique reflections are observed in the co-crystal X-ray powder diffractogram, for instance, at $2 \theta=9.2,10.3,12.8,16.2,18.5,20.7,22.1,24.3$ and $25.7^{\circ}$ (Figure 3). Shifts of the wavenumbers of N-H stretching modes are observed for the cocrystal relative to both pure NA and pure DAP, as well as of the $\mathrm{C}=\mathrm{O}$ stretching mode of NA (Figure S19).

The pure co-crystal could also be obtained in a slurry of the pure components in ethanol, kept at $25^{\circ} \mathrm{C}$ for 2 days (1:3 DAP + NA molar ratio).

\section{General Remarks}

The low propensity of DAP and both TMP and PMA to give rise to co-crystals with the isomeric pyridinecarboxamides, as predicted in the framework of COSMOquick, was confirmed. The DAP + NA exception is certainly a consequence of the greater simplicity of the DAP molecule, hence giving rise to fewer competing supramolecular association possibilities, and of the particular nicotinamide molecular structure. Concerning picolinamide, its lower co-crystal formation propensity when compared to their two isomers, with a different electronic structure in the ring, has been pointed out $[45,46]$.

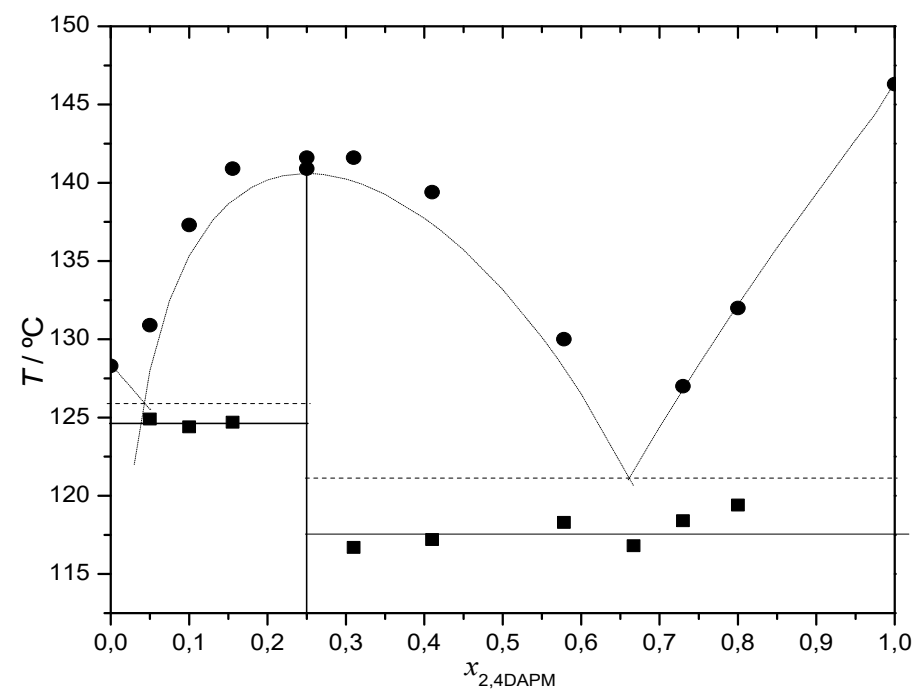

Figure 2. (Solid + liquid) binary phase diagram of DAP + NA; $\mathbf{\square}$ and solid line-experimental solidus; •-experimental liquidus. Dotted lines obtained using eqs. (1) and (2). 


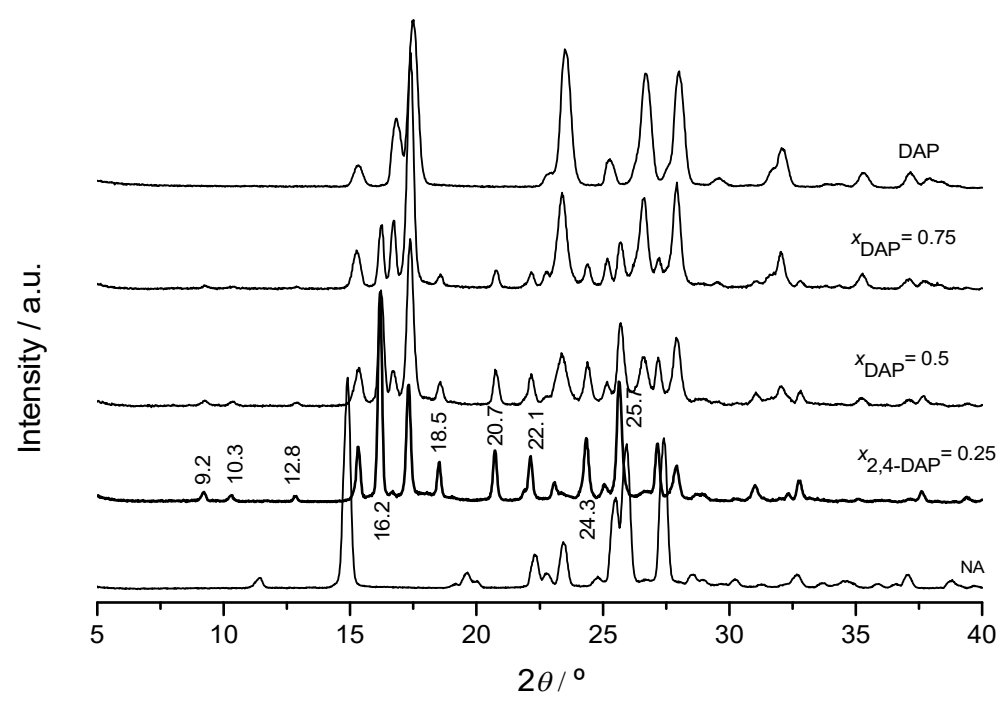

Figure 3. XRP diffractogram of DAP+NA mixtures of different compositions, obtained by LAG, ethanol-assisted.

\section{2. (DAP/TMP/PMA) + (THEO/CAF) Binary Systems}

2.2.1. 2,4-Diaminopyrimidine + theophylline and 2,4-Diaminopyrimidine + caffeine

The representative DSC heating curves of binary mixtures of 2,4-diaminopirimidine + theophylline, prepared by ethanol-assisted grinding, are presented in Figure 4. A complex thermal behavior is observed with evidence of three invariant points, $T_{1}=137^{\circ} \mathrm{C}$, $T_{2}=192{ }^{\circ} \mathrm{C}$ and $T_{3}=218^{\circ} \mathrm{C}$, as indicated in the Figure. This behavior suggests that two co-crystals should be identified for this system.

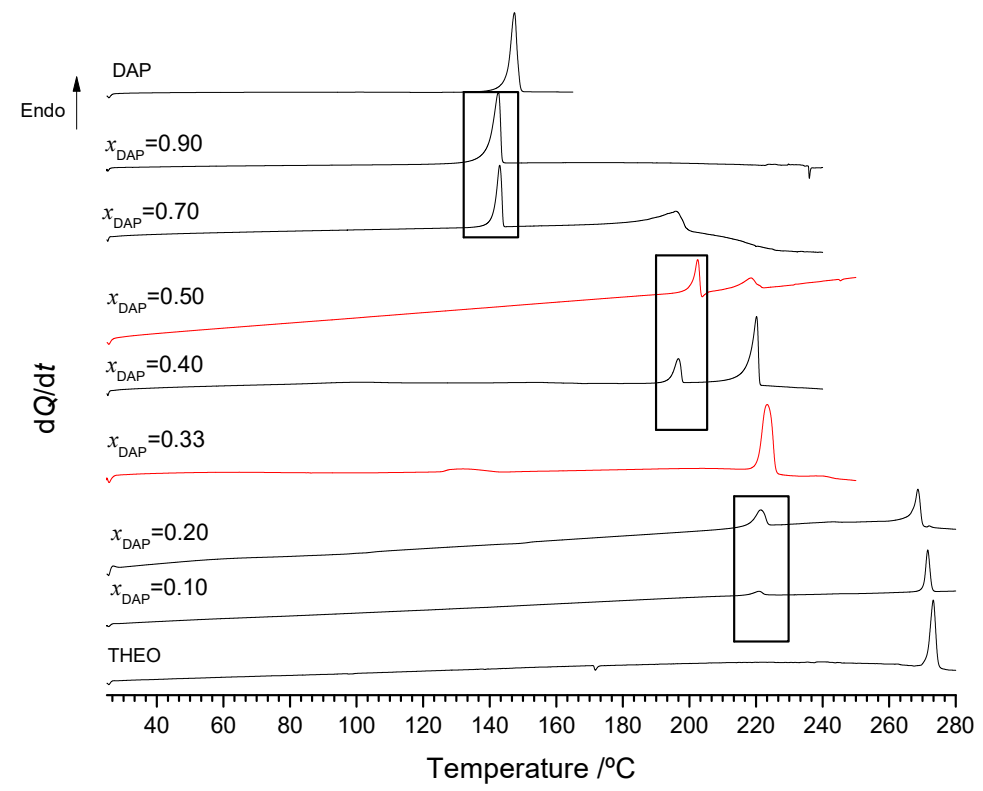

Figure 4. Representative DSC heating curves of DAP + THEO mixtures of different DAP mole fractions, $x_{\mathrm{DAP}}$, prepared by LAG, ethanol-assisted. $\beta=10^{\circ} \mathrm{C} / \mathrm{min}^{-1}$.

This is confirmed by X-ray powder diffractograms (Figure 5) that show unique patterns with no excess of either of the initial compounds for the (1:2) and (1:1) DAP:THEO mixtures $\left(x_{\mathrm{DAP}}=0.33\right.$ and 0.50 , respectively), indicating the formation of different multiple component solid forms with those stoichiometries. Unique reflections are observed for the (1:2) DAP:THEO solid at $2 \theta=6.7,6.9,9.5,9.9,13.5,13.9,24.7$ and $25.7^{\circ}$, for instance, and for the (1:1) multicomponent solid at $2 \theta=6.4,9.9,13.0,17.9,18.3,21.6,26.1,27.4$ and $28.6^{\circ}$. For 
mixtures with $x_{\mathrm{DAP}}<0.33$, reflections due to theophylline are observed (besides those due to the (1:2) solid form); for $x_{\mathrm{DAP}}>0.5$, reflections of the (1:1) new solid form are seen and the excess of DAP is clearly identified. The $\mathrm{X}$-ray powder diffractogram of the $x_{\mathrm{DAP}}=0.4$ mixture shows reflections of both (1:2) and (1:1) solid forms. The same conclusions are achieved by analysis of the FTIR spectra of representative mixtures shown in Figure S20.

Thermogravimetric analysis (Figure 6) indicates that the (1:2) co-crystal is a solvated one (see also Figures S21 and S22). The same X-ray powder diffractogram was obtained for a (1:2) DAP + THEO sample grinded with ethyl acetate assistance. The mass loss of about $1.5 \%$ observed in the TG curve is compatible with a (1:2:0.5) DAP:THEO: $\mathrm{H}_{2} \mathrm{O}$ multicomponent solid.

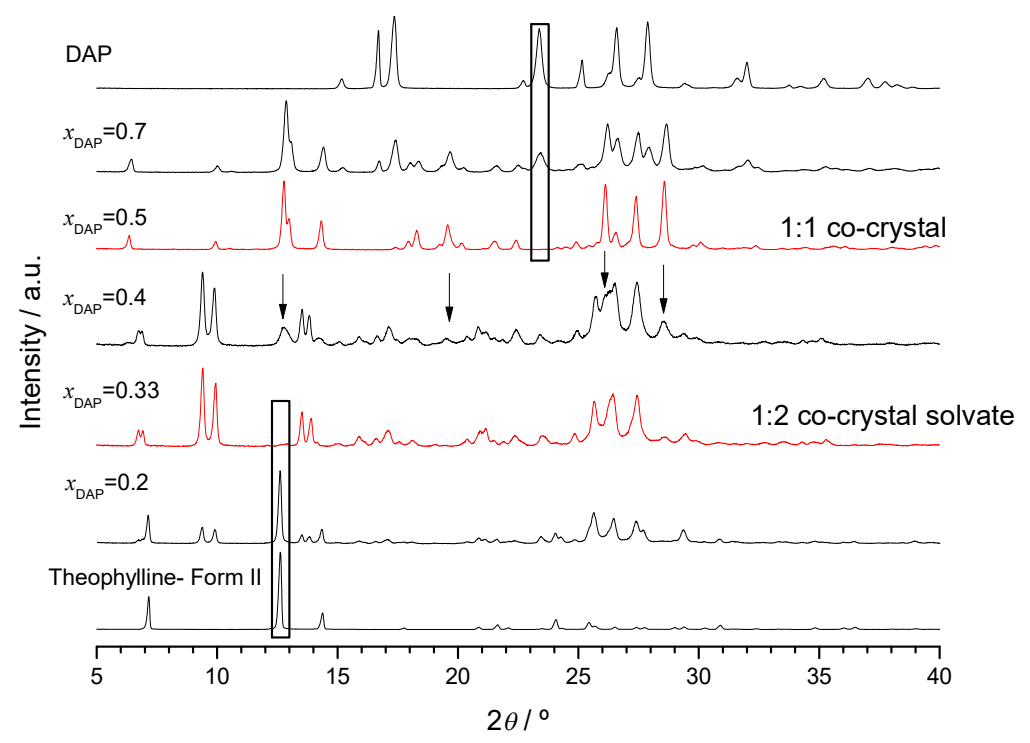

Figure 5. X-ray powder diffractograms of representative DAP + THEO mixtures prepared by ethanolassisted grinding.

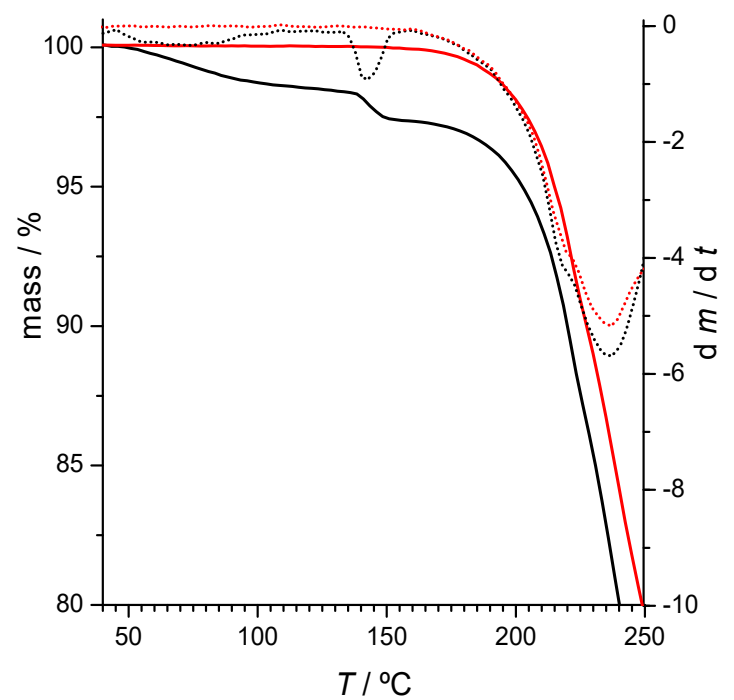

Figure 6. Thermogravimetric (solid lines) and derivative thermogravimetric (dotted lines) curves of $x_{\mathrm{DAP}}=0.33$ mixtures prepared by ethanol-assisted grinding (black lines) and by neat grinding (red lines), open pans.

The results obtained for $\mathrm{x}_{\mathrm{DAP}}=0.50$ are the same when neat grinding is performed (Figure S23, ESI). However, neat grinding experiments carried out on (1:2) DAP + THEO mixtures give rise, as expected, to a solid form different from that obtained by LAG. 
This form is anhydrous (Figure 6) and has characteristic reflections in the X-ray powder diffractogram at $2 \theta=7.4,8.2,13.6,14.2,25.1$ and $27.0^{\circ}$ (Figure 7). Interestingly, it gives rise, upon heating, to the same solid form obtained after the dehydration of the LAG-obtained co-crystal (Figure 7) with characteristic reflections at $2 \theta=11.5,13.1,14.7,17.5$ and $26.5^{\circ}$. DSC curves are shown in Figure S21.

A tentative (solid + liquid) binary phase diagram presented in Figure 8 may be proposed where two incongruently melting co-crystals are identified at (1:2) and (1:1) DAP:THEO.

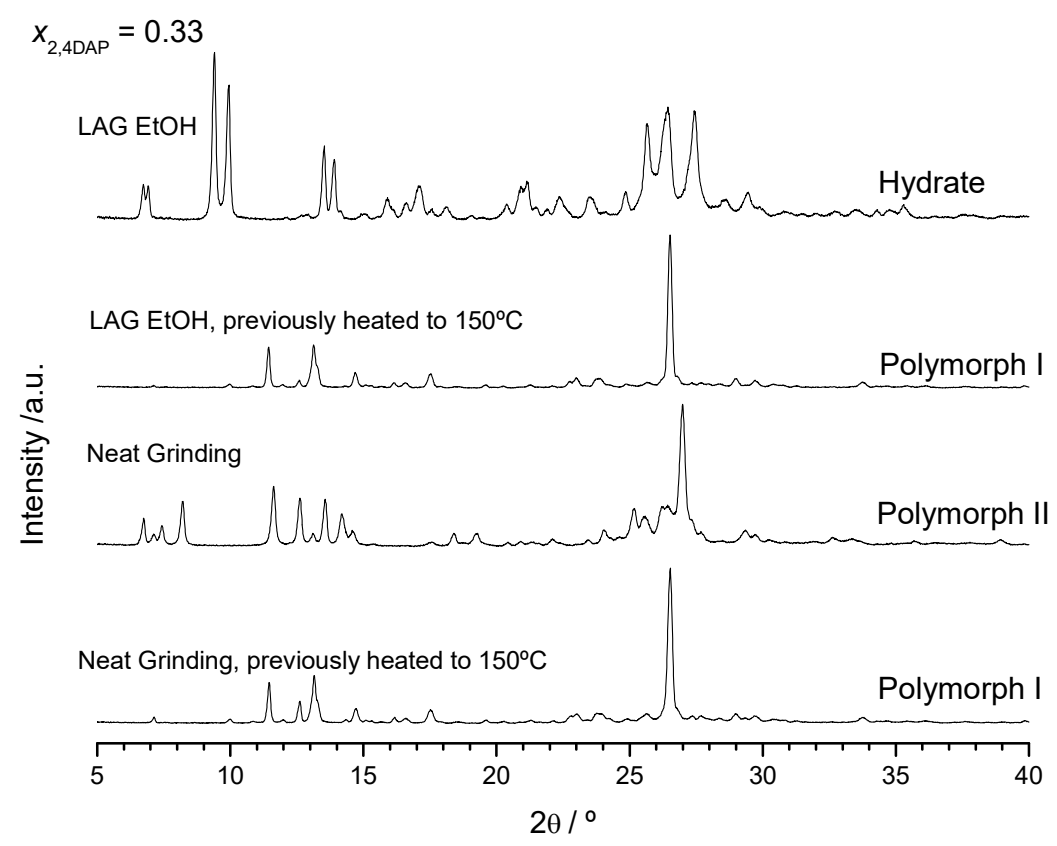

Figure 7. X-ray powder diffractograms of DAP + THEO mixtures, $x_{\mathrm{DAP}}=0.33$, obtained by different experimental methodologies.

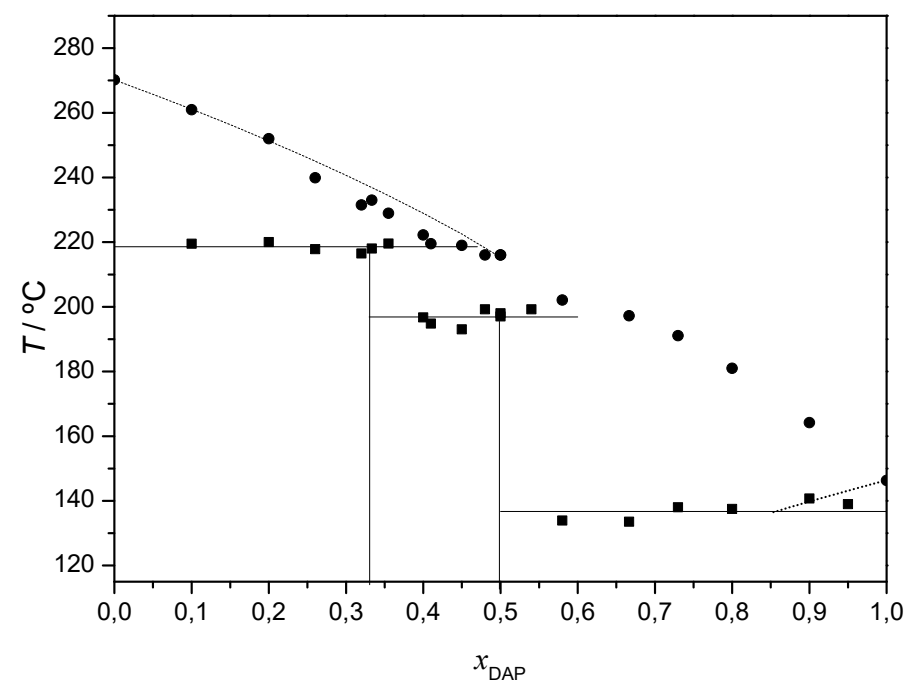

Figure 8. (Solid + liquid) binary phase diagram of DAP + THEO: $\mathbf{\square}$ and solid horizontal lineexperimental solidus; $\bullet-$ experimental liquidus; vertical line—co-crystal composition. Dotted lines obtained using eq. (1).

In conclusion, for the DAP + THEO system, a (1:1) co-crystal was identified, as well as two polymorphic (1:2) co-crystals and a (1:2) DAP:THEO co-crystal hydrate.

Concerning DAP + CAF, in the experimental conditions used in the current work, co-crystal formation was not successful. This is evident from the binary (solid + liquid) 
phase diagram (Figure S24; representative DSC curves shown in Figure S25) and from FTIR spectra (Figure S26).

\subsubsection{Trimethoprim + theophylline and Trimethoprim + caffeine}

The DSC curves shown in Figure 9a and the proposed (solid + liquid) binary phase diagram (Figure 9 b) point to (1:2) TMP:THEO co-crystal formation, which is confirmed by X-ray diffraction and FTIR investigation (Figure 10 and Figure S27, respectively). In these Figures, the excesses of the pure components are indicated by arrows.

(a)

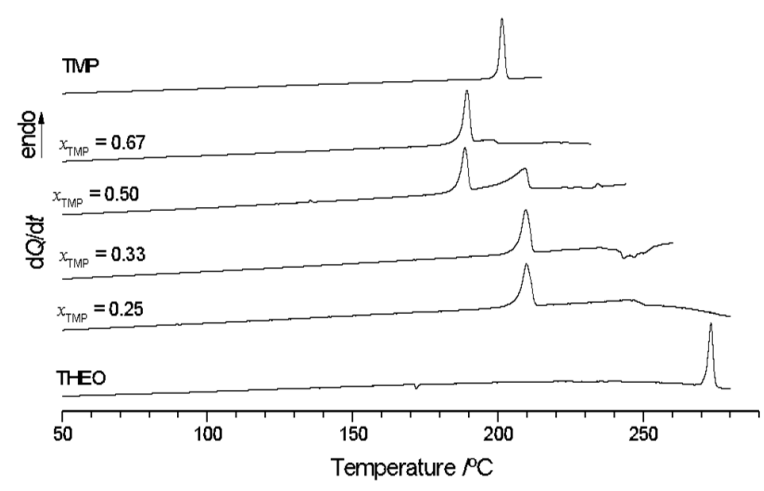

(b)

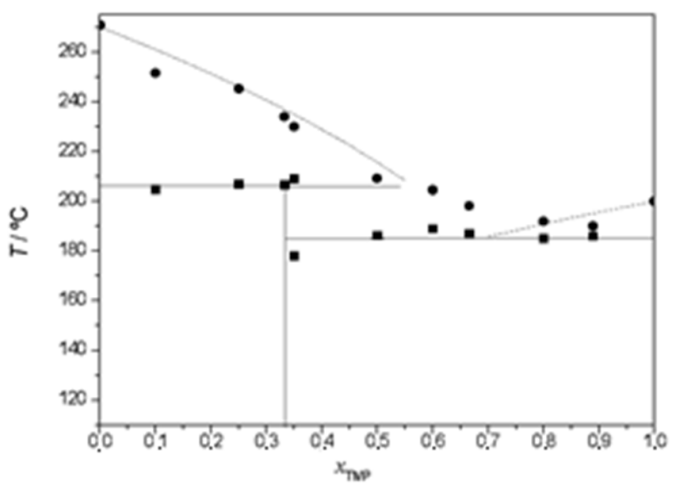

Figure 9. (a) Representative DSC heating curves of TMP + THEO mixtures of different TMP mole fractions, $x_{\mathrm{TMP}}$, prepared by LAG, ethanol-assisted. $\beta=10^{\circ} \mathrm{C} / \mathrm{min}^{-1}$. (b) (Solid + liquid) binary phase diagram of TMP + THEO $\mathbf{\square}$ and solid horizontal line-experimental solidus; •-experimental liquidus; vertical line—co-crystal composition. Dotted lines obtained using eq. (1).

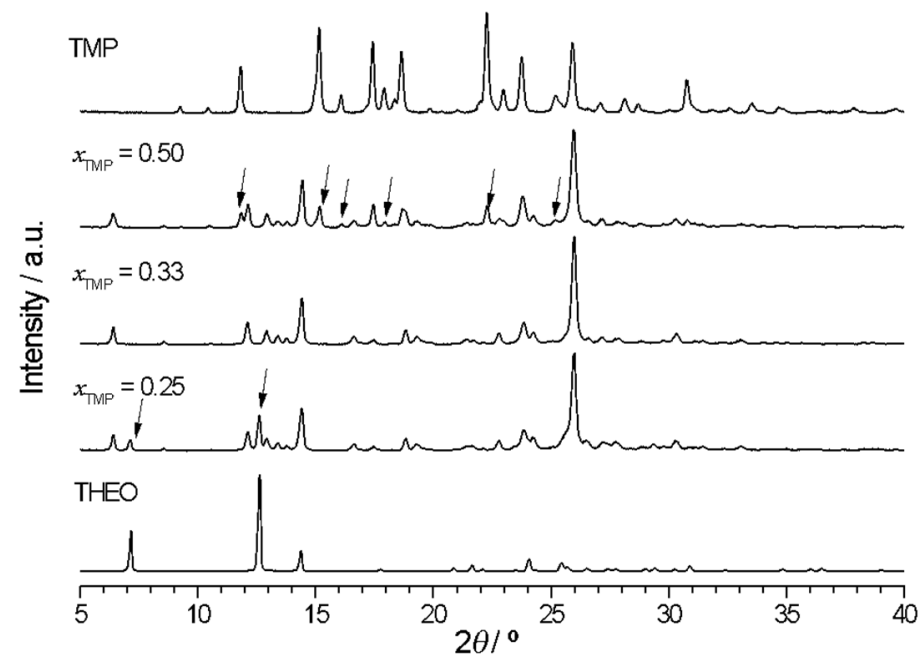

Figure 10. X-ray powder diffractogram of TMP + THEO mixtures of different compositions, obtained by LAG, ethanol-assisted.

The thermogravimetric curve of the co-crystal (Figure 11) shows only a residual mass loss. 


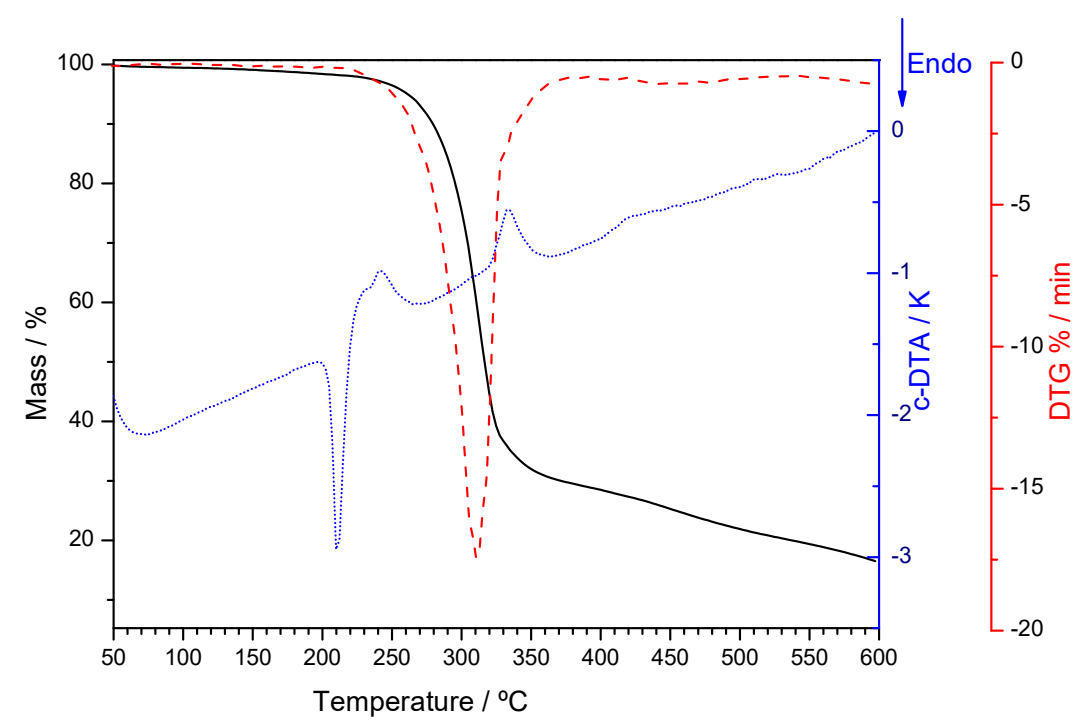

Figure 11. Thermogravimetric curve (solid black line), derivative thermogravimetric curve (dashed red line) and DTA heating curve (dotted blue line) of (1:2) TMP:THEO co-crystal.

The crystalline structure of a (1:2) TMP:THEO $\left(17 \% \mathrm{H}_{2} \mathrm{O}\right)$ was solved (CCDC 2109486) as described in Section 3.7 and discussed in Section 2.2.3. The simulated X-ray powder diffractogram for this co-crystal matches the experimental one of the co-crystal obtained by grinding (Figure 12).

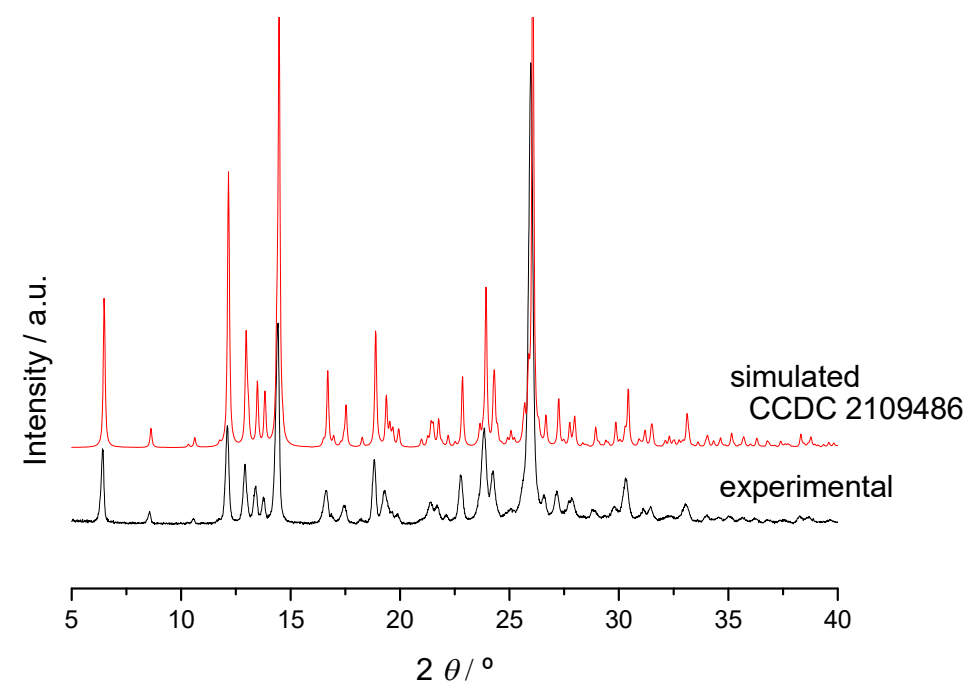

Figure 12. Experimental X-ray powder diffractogram of (1:2) DAP + THEO 1:2 co-crystal and simulated for the $(1: 2)+17 \% \mathrm{H}_{2} \mathrm{O}$ solved structure, CCDC 2109486.

In the experimental conditions used in the current work, as it was also observed for $\mathrm{DAP}+\mathrm{CAF}$, co-crystal formation between trimethoprim and caffeine was not successful (see Figures S28-S30).

\subsubsection{Crystalline Structures and Hirshfeld Surfaces Analysis}

A comparison of the propensity for co-crystal formation with a common set of coformers was performed in the preceding sections for the DAP scaffold and the derived dihydrofolate reductase inhibitors, trimethoprim and pyrimethamine. A comparison of the intermolecular association in crystals of DAP, TMP and PMA with the same set of co-formers is, naturally, also of interest.

Several attempts, using different experimental approaches, were tried in order to obtain single crystals of the multicomponent solids identified in this work that are suitable for 
crystal structure resolution. This is a hard task, with unpredictable successful results. Single crystals of the (1:2) TMP:THEO co-crystal could be obtained, as described in Section 3.7, and its crystalline structure solved. Additionally, when searching for DAP:THEO co-crystals, single crystals of a new (1:2:1) DAP:THEO:EtAc solvate were obtained. Crystallographic data for both structures are presented in Section 3.7. A comparison of the intermolecular association in these two new crystalline structures, with the same co-former, is presented in this section. Comparison is also made with the (1:1) PMA:THEO co-crystal structure solved by Delori et al. [28].

The ORTEP diagram, with the numbering scheme for (1:2:1) DAP:THEO:EtAc solvate, is shown in Figure 13. The unit cell and illustrative images of the crystalline arrangement and of the intermolecular hydrogen bonds are shown in Figure 14 and in Table 2.

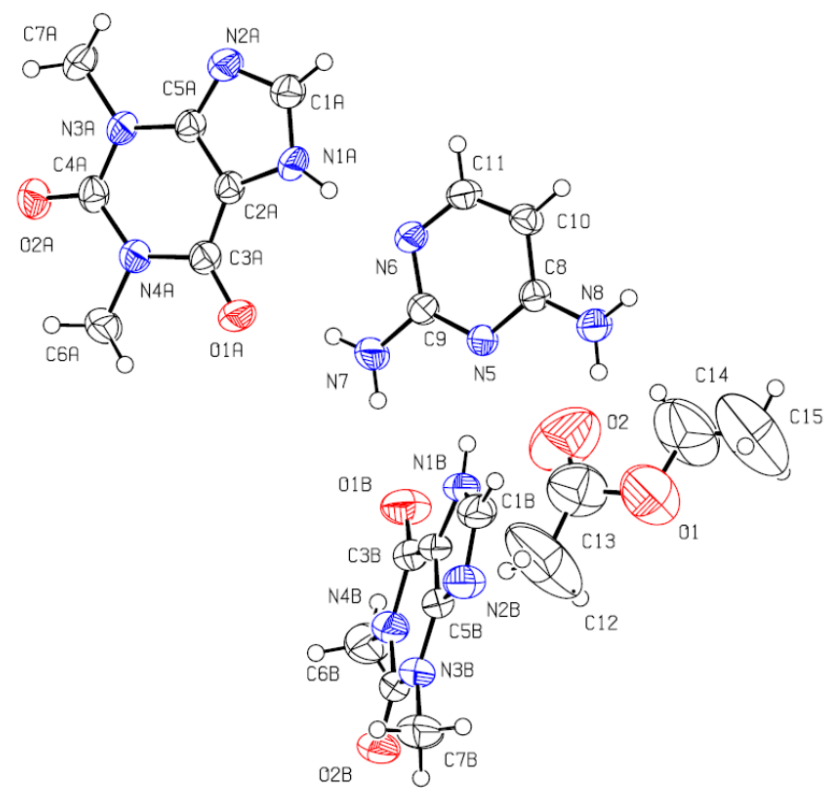

Figure 13. ORTEP diagram of the (1:2:1) 2,4-diaminopyrimidine:theophylline:ethyl acetate, CCDC 2108308. Ellipsoids are drawn at the $50 \%$ probability level. Hydrogen atoms are drawn as spheres of arbitrary radius.

a)

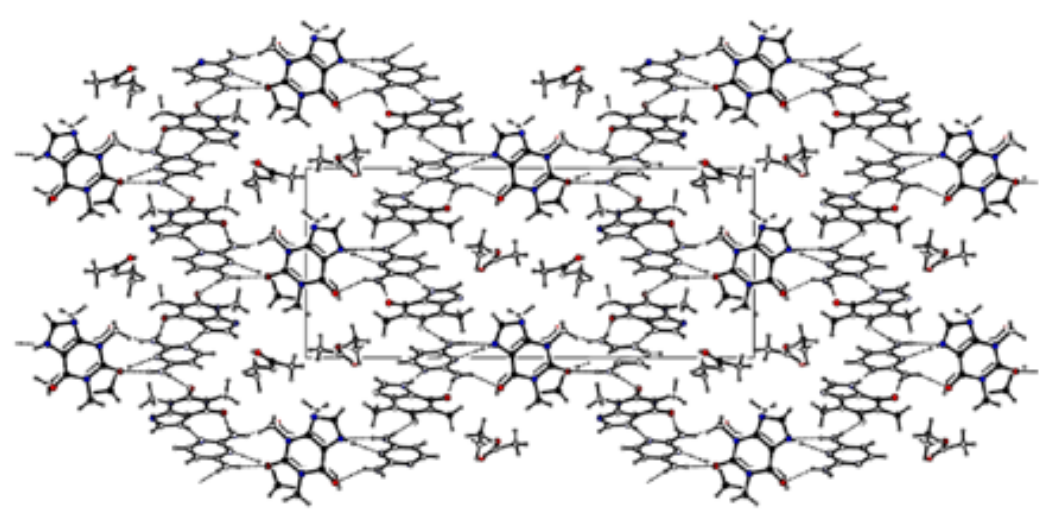

b)

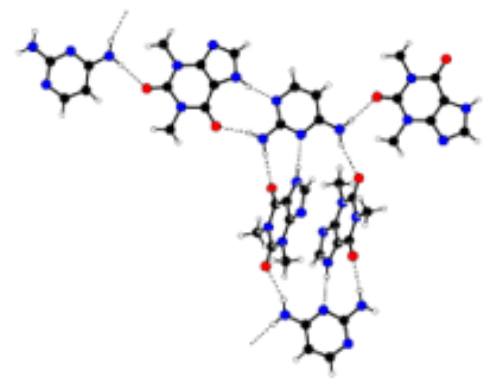

Figure 14. (a) Packing diagram for (1:2:1) DAP:THEO:EtAc viewed along the a axis. (b) Detail of the hydrogen bonded ribbons that join the 2,4-diaminopyrimidine and the theophylline molecules. 
Table 2. Hydrogen bonds in (1:2:1) DAP:THEO:EtAc solvate.

\begin{tabular}{|c|c|c|c|c|}
\hline D-H $\cdots A$ & D-H/Å & $\mathbf{H} \cdots \mathbf{A} / \AA ̊$ & $\mathbf{D} \cdots \mathbf{A} / \AA ̊ ̊$ & $\mathbf{D}-\mathbf{H} \cdots \mathbf{A} /^{\circ}$ \\
\hline \multicolumn{5}{|c|}{ (1:2:1) DAP:THEO:EtAc } \\
\hline N1A-H1A $\cdots$ N6 & 0.86 & 1.91 & $2.760(3)$ & 171 \\
\hline N1B-H1B $\cdots$ N5 & 0.86 & 2.05 & $2.907(3)$ & 178 \\
\hline N7-H7A $\cdots$ O1A & 0.86 & 2.11 & $2.957(3)$ & 167 \\
\hline N7-H7B $\cdots$ O1B & 0.86 & 2.20 & $2.992(3)$ & 152 \\
\hline N8-H8A $\cdots$ O $2 B^{a}$ & 0.86 & 2.16 & $2.970(3)$ & 156 \\
\hline $\mathrm{N} 8-\mathrm{H} 8 \mathrm{~B} \cdots \mathrm{O} 2 \mathrm{~A}^{\mathrm{b}}$ & 0.86 & 2.08 & $2.932(3)$ & 174 \\
\hline \multicolumn{5}{|c|}{$a:-1-x,-y, 1-z ; b: 2+x, 1 / 2-y, 1 / 2+z$} \\
\hline
\end{tabular}

The molecules crystallize in a monoclinic crystal structure, under the common $\mathrm{P} 21 / \mathrm{c}$ space group. The 2,4-diaminopyrimidine and the theophylline molecules are joined together in ribbons, with each 2,4-diaminopyrimidine molecule H-bonded to four theophylline molecules (Figure 14b and Table 2). The planar ribbons containing the DAP molecules are interconnected by skewed THEO molecules (an angle of $47.1^{\circ}$ is observed between the DAP ring plane and that of these theophylline molecules). The ribbons run along the (100) direction, forming channels that are occupied by the ethyl acetate solvent molecules. Concerning the solvent molecules, very weak contacts [47], only with theophylline molecules, are observed $(\mathrm{O} 2 \cdots \mathrm{H} 1 \mathrm{AC} 1 \mathrm{~A}: \mathrm{O} 2 \cdots \mathrm{H} 1 \mathrm{~A}=2.457 \AA ; \mathrm{O} 2 \cdots \mathrm{C} 1 \mathrm{~A}=3.388 \AA$, $\mathrm{O} 2 \cdots \mathrm{H} 1 \mathrm{~A}-\mathrm{C} 1 \mathrm{~A}=179.5^{\circ} ; \mathrm{C} 14 \mathrm{H} 14 \mathrm{~B} \cdots \mathrm{N} 2 \mathrm{~A}: \mathrm{H} 14 \mathrm{~B} \cdots \mathrm{N} 2 \mathrm{~A}=2.625 \AA$; $\mathrm{C} 14 \cdots \mathrm{N} 2 \mathrm{~A}=3.461 \AA$, $\mathrm{C} 14-\mathrm{H} \cdots \mathrm{N} 2=145.7^{\circ} ; \mathrm{C} 15 \mathrm{H} 15 \mathrm{~A} \cdots \mathrm{O} 1 \mathrm{~B}: \mathrm{H} 15 \mathrm{~A} \cdots \mathrm{O} 1 \mathrm{~B}=2.713 \AA ; \mathrm{C} 15 \cdots \mathrm{O} 1 \mathrm{~B}=3.492 \AA, \mathrm{C} 15$ $\mathrm{H} 15 \mathrm{~A} \cdots \mathrm{O} 1 \mathrm{~B}=138.6$ ). There are no intermolecular hydrogen bonds between DAP molecules.

The close contacts involving the DAP molecule in the co-crystal are highlighted in its Hirshfeld surface, shown in Figure 15a, and consist of six H-bonds. In four of these, the DAP $\mathrm{NH}_{2}$ groups act as donors to different THEO O=C groups, and in the other two, each $\mathrm{N}$ atom in the ring acts as acceptor from the $\mathrm{NH}$ groups of two THEO molecules.

The four $\mathrm{NH}$... O interactions are expressed in the left spike of the fingerprint plot in Figure 15b. The tip of the spike corresponds to the stronger $\mathrm{H}$ bonds, towards the approximately co-planar THEO molecules in the above-mentioned ribbons. The two $\mathrm{N} \cdots \mathrm{HN}$ contacts, identified as the right spike in the plot, follow the same trend, with stronger $\mathrm{H}$ bonding involving the ribbon THEO molecules. It is worth mentioning the green area close to $d_{\mathrm{i}} \approx d_{\mathrm{e}}=1.8 \AA$ correspond to heavy atom contacts due to DAP...THEO $\pi-\pi$ stacking interactions [48].

Single crystals of a (1:2) trimethoprim theophylline (partially solvated) co-crystal were obtained as described in Section 3.7. The ORTEP diagram, with the numbering scheme, is shown in Figure 16 and in the unit cell, and illustrative images of the crystalline arrangement and of the intermolecular hydrogen bonds are shown in Figure 17 and in Table 3.

The molecules of trimethoprim and theophylline are joined in chains by $\mathrm{H}$-bonds. One of the chains is assembled by the trimethoprim and one of the two theophylline independent molecules (Figure 17b). The other theophylline independent molecules form a different chain (Figure 17c). In this planar chain, the theophylline molecules are joined by N5B-H5B $\cdots$ N6B hydrogen bonds, as in pure theophylline polymorph II, CCDC128707 [49], although, in pure THEO, the molecules are not in the same plane (Figure S31). The chains pack parallel to each other (see Figure 17a; structure viewed along the $b$ axis). An oxygen atom (water molecule) is located close to one of the amine groups of trimethoprim, but with just a $17 \%$ occupation, accounting for a weak solvation. It is possible that the $17 \%$ of occupation found in the refinement of the data coming from a single data collection is just a "snapshot" of a continuous series of possible solvent/compound ratios. There is evidence that this non-stoichiometric solvate can desolvate to the two-component phase without changing the main structural characteristics, since powder diffractograms collected before and after forced hydration do not change (Figure S32). It is even possible that the 
water molecules escape the lattice at room temperature due to their small size and weak interactions within the crystal main structure.

There is only a small change in trimethoprim conformation in the co-crystal with an angle of $80^{\circ}$ between the planes of the two rings, slightly greater than in pure TMP crystals, $70^{\circ}$ (CCDC607118 [50]). In the co-crystal, as in pure trimethoprim [50], the oxygen (O2) of the middle methoxy group is hydrogen-bonded to a NH group of a different TMP molecule, N4H4 in the co-crystal and N3H3 in pure TMP. As in the (1:2:1) DAP:THEO:EtAc structure, no $\mathrm{NH} \cdots \mathrm{N}$ hydrogen bonds involving the aminopyrimidine scaffold are observed between TMP molecules.
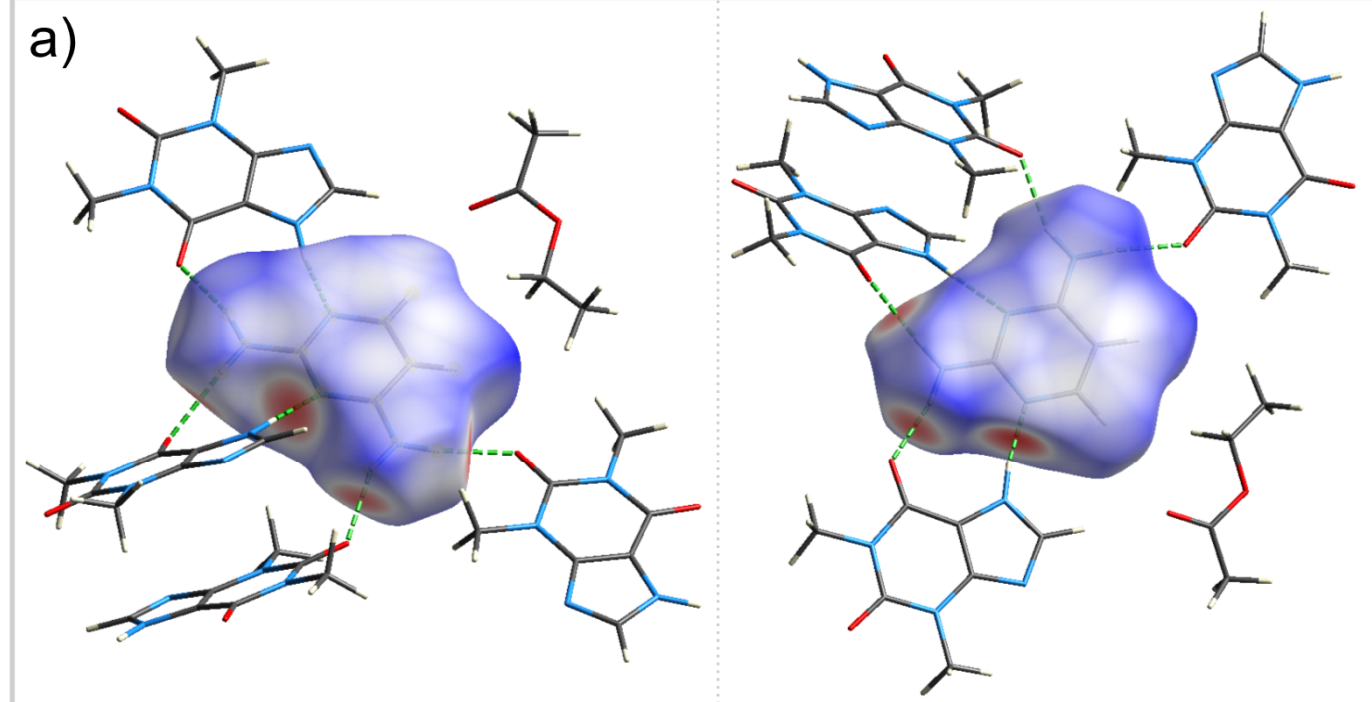

b)

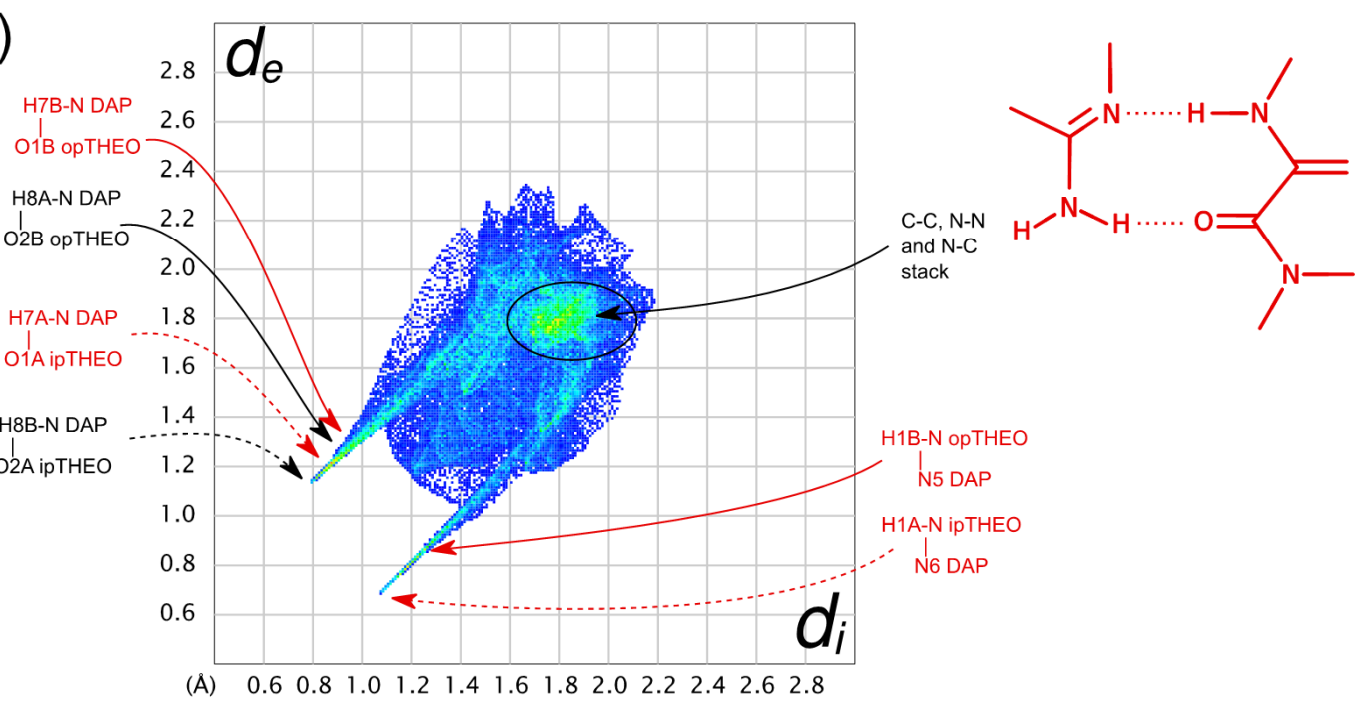

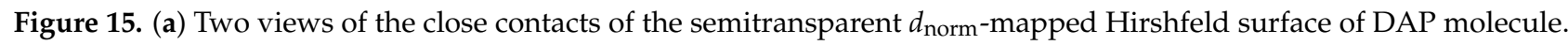
(b) Hirshfeld fingerprint plot of the DAP molecule in the (1:2:1) DAP:THEO:EtAc co-crystal solvate. Some important pairs of contacting atoms are identified and assigned to fingerprint plot features, with dashed arrows for "in-plane" (ipTHEO) and solid arrows for "out-of-plane" (opTHEO) THEO molecules. Contacts within the $R_{2}^{2}(9)$ synthon between the DAP scaffold and THEO, shown at the side, are colored in red. $d_{\mathrm{i}}$ - the distance $(\AA)$ from the Hirschfeld surface to the nearest atom center in its interior; $d_{\mathrm{e}}$-distance $(\AA)$ from the Hirschfeld surface to the nearest atom center in its exterior. 


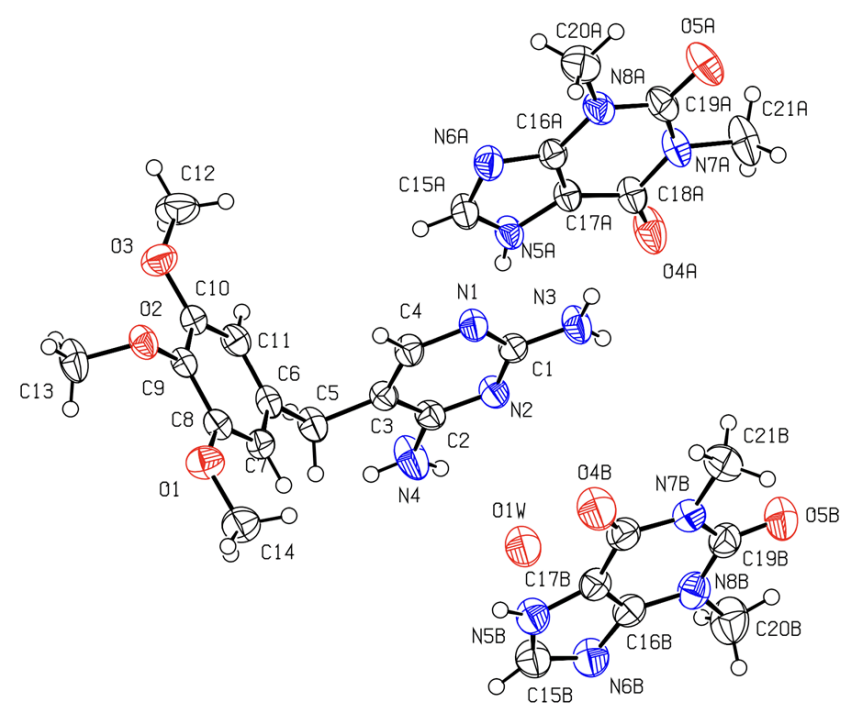

Figure 16. ORTEP diagram of the (1:2) trimethoprim:theophylline, CCDC 2109486. Ellipsoids are drawn at the $50 \%$ probability level. Hydrogen atoms are drawn as spheres of arbitrary radius.

a)

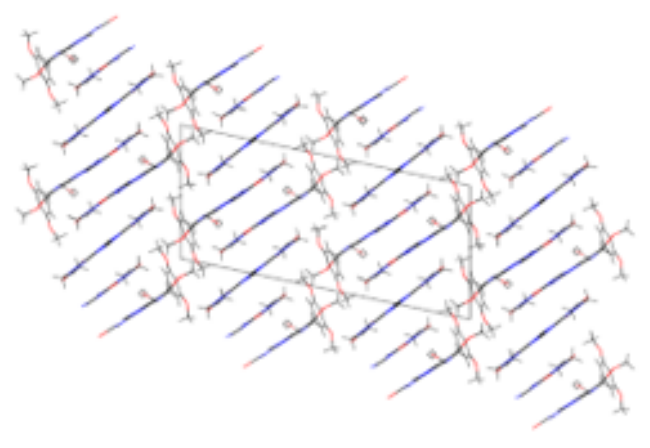

c)

) b)

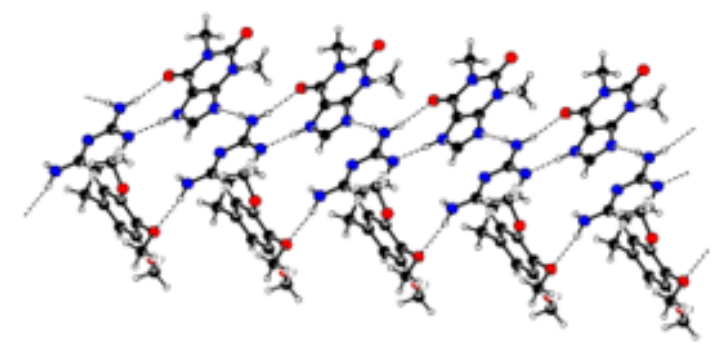

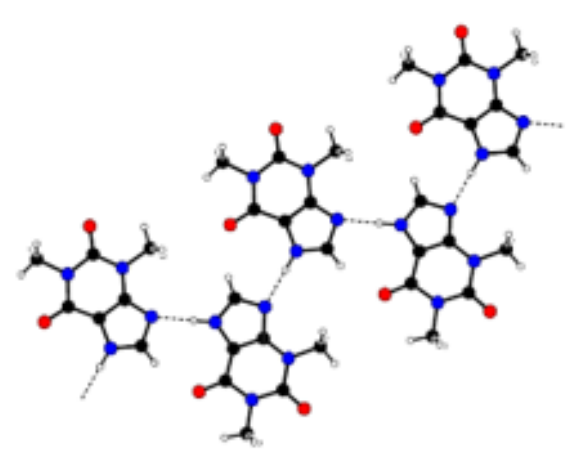

Figure 17. (1:2) trimethoprim:theophylline, CCDC 2109486: (a) Unit cell packing viewed along the b axis; (b) hydrogen bonded chains joining trimethoprim and theophylline molecules; (c) hydrogen bonded chains joining the second theophylline molecule. 
Table 3. Geometric parameters of hydrogen bonds for (1:2) trimethoprim:theophylline. ( $D$ and $A$ are the donor and the acceptor atoms, respectively.)

\begin{tabular}{|c|c|c|c|c|}
\hline D-H $\cdots A$ & D-H/Å & $\mathbf{H} \cdots \mathbf{A} / \mathbf{A}$ & $\mathrm{D} \cdots \mathbf{A} / \AA$ & $\mathbf{D}-\mathbf{H} \cdots \mathbf{A} /^{\circ}$ \\
\hline $\mathrm{N} 3-\mathrm{H} 3 \mathrm{~A} \cdots \mathrm{N}^{2} \mathrm{~A}^{i}$ & 0.86 & 2.21 & $3.064(2)$ & 171 \\
\hline N3-H3B $\cdots$ O4A & 0.86 & 2.09 & $2.933(2)$ & 166 \\
\hline $\mathrm{N} 4-\mathrm{H} 4 \mathrm{~B} \cdots \mathrm{O} 2^{i}$ & 0.86 & 2.23 & $2.927(2)$ & 139 \\
\hline N5A-H5A $\cdots \mathrm{N} 1$ & 0.86 & 1.97 & $2.820(2)$ & 170 \\
\hline N5B-H5B $\cdots \mathrm{N}^{2} \mathrm{~B}^{\mathrm{v}}$ & 0.86 & 1.90 & $2.762(2)$ & 175 \\
\hline \multicolumn{5}{|c|}{$i: x,-1+y, z ; i i:-x, 1 / 2+y, 1 / 2-z$} \\
\hline
\end{tabular}

The Hirshfeld surface of the TMP molecule in TMP:THEO, presented in Figure 18a and in the fingerprint plot (Figure 18b) show similar features to DAP in the previously mentioned co-crystal. The evidence of different donating and accepting $\mathrm{H}$ bonds are manifested in the complex structure of their two corresponding spikes. In both co-crystals, the $\mathrm{NH} \cdots \mathrm{N}$ type between the $\mathrm{NH}$ group of THEO and one of the ring $\mathrm{N}$ atoms of the diaminopyrimidine scaffold is the strongest interaction- $\left(d_{\mathrm{i}}, d_{\mathrm{e}}\right) / \AA \approx(1.1,0.7)$-despite carbonyl generally being a better acceptor of $\mathrm{H}$ bonding than aromatic ring nitrogen. It is worth mentioning that in both of the co-crystal structures solved in this work, the synthon that is specially highlighted in Figures 15 and 18 plays a major role. This synthon is also observed in the (1:1) PMA:THEO co-crystal structure solved by Delori et al. [28]. In this latter co-crystal, of a different stoichiometry, PMA homodimers are observed. The presence of $\pi-\pi$ stacking is noticed in both Hirshfeld surfaces around $d_{\mathrm{i}} \approx d_{\mathrm{e}}=1.8 \AA$.
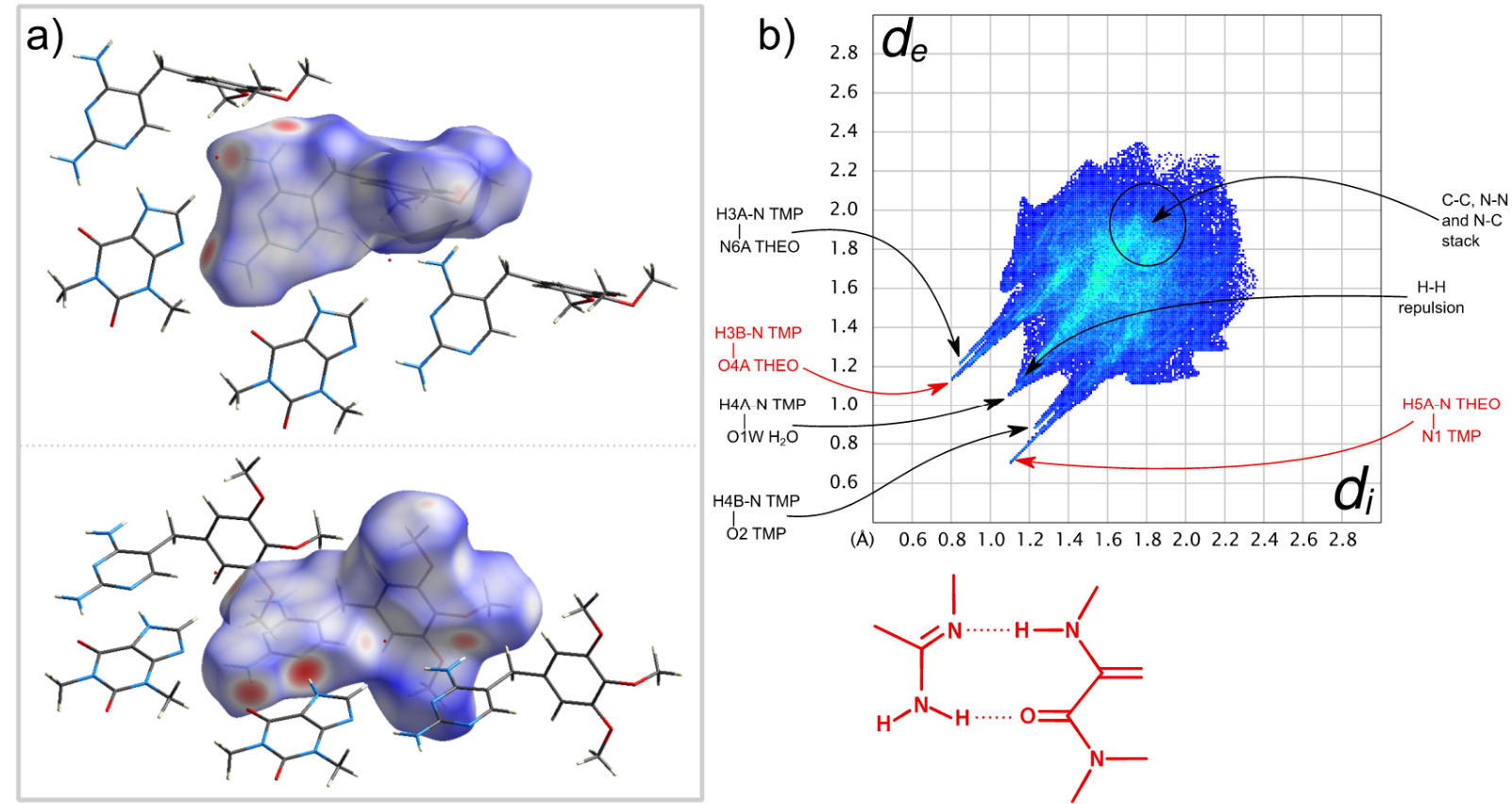

Figure 18. (a) Two views of the semitransparent $d_{\text {norm }}$-mapped Hirshfeld surface of a TMP molecule; (b) Hirshfeld fingerprint plot of the TMP molecule in the (1:2) TMP:THEO $\left(17 \% \mathrm{H}_{2} \mathrm{O}\right)$ co-crystal. Some important pairs of contacting atoms are identified and assigned to fingerprint plot features. Contacts within the $R_{2}^{2}(9)$ synthon between the DAP scaffold and THEO, shown at the bottom, are colored in red. $d_{\mathrm{i}}$ - the distance $(\AA)$ from the Hirschfeld surface to the nearest atom center in its interior; $d_{\mathrm{e}}$-distance $(\AA)$ from the Hirschfeld surface to the nearest atom center in its exterior.

\subsubsection{General Remarks}

The co-crystal screening resulted in the successful synthesis of multicomponent solid forms of all three target molecules with theophylline. DAP co-crystals revealed a greater 
variety of stoichiometries (1:1, 1:2 DAP:THEO) and even polymorphism in the case of the 1:2 stoichiometry. Likewise, theophylline was a viable co-former with TMP, however with a single form of 1:2 TMP:THEO stoichiometry. This concurs with previous findings, where two co-crystal polymorphs were obtained for (1:1) PMA:THEO [27,28].

The crystalline structure of the (1:2) TMP:THEO was resolved in this work, as well as an ethyl acetate solvate of DAP:THEO in the same stoichiometry. Both structures lack hydrogen bonding between the aminopyrimidine scaffolds, and both share the common synthon described above in Figure 1j. and previously recognized in PMA:THEO [28]. This synthon, a $R_{2}^{2}(9)$ hydrogen bonding motif, identified in Figures 15 and 18, involves the NH group of theophylline as a hydrogen bonding donor. Contrary to theophylline, caffeine has no hydrogen-bonding donor groups, which could be a possible reason for its weaker co-former performance with the target compounds. It could not form co-crystals with either DAP or TMP, despite the previously reported successful synthesis of a polymorphic (1:1) co-crystal with PMA [27]. In both of these latter PMA co-crystals, the hydrogen bonds among pyrimethamine molecules involve all 2,4-diaminopyrimidine donor and acceptor groups in a ribbon pattern that is similar to that observed in pyrimethamine polymorph I [51].

\section{Experimental Procedures}

\subsection{Materials}

2,4-Diaminopyrimidine was supplied by TCI Europe, $x>0.98$ and confirmed by XRPD to be the solid form described by Hützler et al. [37] (CCDC 1499993). Pyrimethamine was from Aldrich (St. Louis, MO, USA) (form I [27], CCDC 193733 [51]), specified chemical purity $x=0.9899$, and trimethoprim from Sigma Aldrich (St. Louis, MO, USA), $x>0.98$, crystal structure CCDC 607118, solved by Rauf et al. [52]. Nicotinamide (Form I, [53] picolinamide (polymorph II, [54,55]), isonicotinamide (polymorph I, reference code EHOWIH01 [56]) and theophylline, (Form II CCDC 128707 [49], were all from Aldrich (St. Louis, MO, USA) with specified purities, namely, $x=0.995,0.98,0.99$ and 0.99 , respectively. Caffeine, $x \geq 0.99$, form II CCDC 610381 [57], was acquired from Fluka (Charlotte, NC, USA). Ethanol and ethyl acetate (EtAc), both $x=0.998$, were from Fischer (Hampton, NH, USA). Poly(ethylene oxide) (PEO), MW = 600,000, from Sigma (St. Louis, MO, US), was used in gel crystallization experiments.

\subsection{Co-Crystals Screening}

A preliminary co-crystal in silico screening was carried out using the BIOVIA COSMOquick 2020 software (Vélizy-Villacoublay, France) [40,41]. COSMOquick relies on the COSMOfrag fragmentation approach which employs a database of previously computed $\sigma$-profiles [58] for a set of about 190,000 compounds and its estimation of thermodynamic properties, avoiding the use of costly quantum mechanical calculations, to implement its cocrystal screening capability. The propensity for cocrystal formation is estimated from the excess enthalpy of the virtually subcooled liquid mixture of the components. In order to account for the negative effect of conformational flexibility in cocrystal formation, a partial empirical function based on the number of rotatable torsions is introduced that punishes highly flexible compounds in a screening.

Mechanochemistry was chosen for the experimental co-crystals screening. A MM400 Retsch ball mill, with $10 \mathrm{~mL}$ stainless steel jars and two $7 \mathrm{~mm}$ diameter stainless balls per jar, was used. Typically, a total mass of $\sim 70 \mathrm{mg}$ was used, and grinding was performed neat or with the assistance of $10 \mu \mathrm{L}$ ethanol, at 15 or $30 \mathrm{~Hz}$, for times ranging from 30 to $90 \mathrm{~min}$.

\subsection{Differential Scanning Calorimetry (DSC)}

DSC experiments were carried out using a Perkin Elmer DSC7 (Norwalk, CT, USA) calorimeter, with an intracooler unit at $-10{ }^{\circ} \mathrm{C}$ (ethylene glycol-water $1: 1 v / v$ cooling mixture), and a $20 \mathrm{~mL} / \mathrm{min}^{-1}$ nitrogen purge. Aluminum pans suitable for volatile substances (Perkin Elmer, $30 \mu \mathrm{L}$ ) were employed, with an empty pan as reference. Temperature and 
enthalpy calibrations were performed with certified reference materials, following the procedure described elsewhere [59]. Heating rates of $10^{\circ} \mathrm{C} / \mathrm{min}^{-1}$ were used. The DSC curves were analyzed with Perkin Elmer Pyris software, version 3.5.

\subsection{Thermogravimetric Analysis (TGA)}

A Netzsch TG 209 F3 (Selb, Germany) Tarsus equipment was employed using alumina pans. Sample masses $m \approx 10 \mathrm{mg}$ were used, and temperature was scanned from 30 to $600{ }^{\circ} \mathrm{C}$ in a $\mathrm{N}_{2}$ atmosphere $(25 \mathrm{~mL} / \mathrm{min})$ at a $\beta=10^{\circ} \mathrm{C} / \mathrm{min}$ scanning rate. Temperature calibration was performed using indium, tin, bismuth, zinc, aluminum and silver standards. Mass and linearity of the balance was verified with standard masses of the order of milligrams. Data was analyzed by Netzsch Proteus Thermal Analysis, version 7.2.0. software.

\subsection{Infrared Spectroscopy (FTIR)}

Infrared spectra were obtained in a ThermoNicolet 380 (Thermo Scientific TM, CA, USA) Fourier transform infrared spectrometer, with a Smart Orbit Diamond Attenuated Total Reflection (ATR) system, 64 scans and a $2 \mathrm{~cm}^{-1}$ spectral resolution.

\subsection{X-ray Powder Diffraction (XRPD)}

Powder diffractograms were obtained using a Rigaku MiniFlex 600 (Tokyo, Japan) diffractometer, $\mathrm{Cu} K \alpha$ radiation $(\lambda=1.540598 \AA$ ) , with a D/teX-Ultra high-speed detector. Calibration was performed using silicon as an external calibrant. A scan range from $3^{\circ}$ to $40^{\circ} 2 \theta$ was used.

\subsection{Single-Crystal X-ray Diffraction (SXD)}

Single crystals of a (1:2:1) 2,4-diaminopyrimide:theophylline:ethyl acetate solvate were obtained from evaporation, at room temperature, of an ethyl acetate solution prepared by dissolving a (2.5:3) DAP:THEO sample and obtained by grinding.

Single crystals of a (1:2) trimethoprim:theophylline co-crystal were obtained by gel crystallization: $13.0 \mathrm{mg}$ of the co-crystal was obtained by grinding $2 \mathrm{~mL}$ ethanol + water $1: 1 \mathrm{v} / \mathrm{v}, 0.08 \mathrm{~g} / \mathrm{L}$ poly(ethylene oxide), following the procedure described by ChoquesilloLazarte and Garcia-Ruiz [60].

In the determination of crystal structures of monocrystals by $\mathrm{X}$-ray diffraction analysis, a Bruker-Nonius Kappa Apex II (Bruker, Karlsruhe, DE) CCD diffractometer was used, using MoK $\alpha$ radiation $(\lambda=0.71073 \AA)$. Structures were solved by direct methods and by conventional Fourier Synthesis (SHELXS-97) [61]. The refinement of the structures was performed by full-matrix least-squares on $\mathrm{F}^{2}$ (SHELXL-97) [62]. Hydrogen atoms attached to carbon atoms were placed at calculated positions and refined as riding. Hydrogen atoms attached to nitrogen atoms were located in a difference Fourier synthesis and their coordinates were freely refined. For the (1:2) TMP:THEO co-crystal, at the final refinement stages, a peak in a difference Fourier map of $1.54 \mathrm{e} / \AA^{3}$ persisted and an oxygen atom was tentatively added to the model, refining to near $17 \%$ occupancy that may correspond to a water molecule whose hydrogen atoms were not located.

A summary of the data collection and refinement details is given in Table 4.

\subsection{Hirshfeld Surfaces Analysis}

The CIF files were used as starting points to generate the Hirshfeld surfaces and fingerprints [63,64] using CrystalExplorer, version 17.5. (University of Western Australia), which was also used for their analysis. CrystalExplorer normalizes the $\mathrm{C}-\mathrm{H}$ and $\mathrm{N}-\mathrm{H}$ bonds as those obtained from neutron diffraction experiments (C-H $1.083 \AA$, N-H $1.009 \AA$ ). The surfaces were generated using a "very high" resolution. 
Table 4. Crystal data and structure refinement parameters of the (1:2:1) DAP:THEO:EtAc and (1:2) TMP:THEO (0.17 $\left.\mathrm{H}_{2} \mathrm{O}\right)$ co-crystals.

\begin{tabular}{|c|c|c|}
\hline & $\begin{array}{l}\text { (1:2:1) DAP:THEO:EtAc } \\
\text { CCDC2108308 }\end{array}$ & $\begin{array}{c}\text { (1:2) TMP:THEO }\left(0.17 \mathrm{H}_{2} \mathrm{O}\right) \\
\text { CCDC2109486 }\end{array}$ \\
\hline Temperature/K & 293 & 293 \\
\hline Empirical formula & $\mathrm{C}_{22} \mathrm{H}_{30} \mathrm{~N}_{12} \mathrm{O}_{6}$ & $\mathrm{C}_{28} \mathrm{H}_{34} \mathrm{~N}_{12} \mathrm{O}_{7.17}$ \\
\hline Formula weight & 558.58 & 653.46 \\
\hline Wavelength/ & 0.71073 & 0.71073 \\
\hline Crystal system & Monoclinic & Monoclinic \\
\hline Space group & $\mathrm{P} 2{ }_{1} / \mathrm{c}$ & $\mathrm{P} 22_{1} / \mathrm{c}$ \\
\hline$a / \AA$ & $7.4376(10)$ & $12.5845(6)$ \\
\hline$b / \AA$ & $29.309(4)$ & $9.0152(4)$ \\
\hline$c / \AA$ & $13.4200(14)$ & 27.8422(13) \\
\hline$\beta /^{\circ}$ & $112.968(6)$ & 101.9030(10) \\
\hline Volume $/ \AA^{3}$ & $2693.5(6)$ & $3090.8(2)$ \\
\hline $\mathrm{Z}$ & 4 & 4 \\
\hline Calculated density $/\left(\mathrm{g} / \mathrm{cm}^{3}\right)$ & 1.377 & 1.404 \\
\hline Absorption coefficient $/ \mathrm{mm}^{-1}$ & 0.104 & 0.105 \\
\hline$F(000)$ & 1176 & 1374 \\
\hline$\theta$ range for data collection/deg. & $2.15-25.49$ & $1.49-25.72$ \\
\hline Index ranges & $\begin{array}{c}-8<\mathrm{h}<9,-35<\mathrm{k}<35 \\
-16<1<16\end{array}$ & $-15<\mathrm{h}<15,-10<\mathrm{k}<10,-33<1<33$ \\
\hline Reflections collected/unique & $28210 / 4963$ & $57612 / 5861$ \\
\hline Completeness to $\theta_{\max }$ & $99.9 \%$ & $99.6 \%$ \\
\hline Data/restraints/parameters & $4963 / 0 / 367$ & $5861 / 0 / 454[R(\mathrm{int})=0.0293]$ \\
\hline Goodness-of-fit on $\mathrm{F}^{2}$ & 1.030 & 1.025 \\
\hline Final $\mathrm{R}$ index $[\mathrm{I}>2 \sigma(\mathrm{I})]$ & $R 1=0.0599 w R 2=0.1428$ & $R 1=0.0388 w R 2=0.1052$ \\
\hline $\mathrm{R}$ index (all data) & $R 1=0.1140 w R 2=0.1744$ & $R 1=0.0484 w R 2=0.1144$ \\
\hline Largest diff. peak and hole $\left(\mathrm{e} \AA^{-3}\right)$ & -0.296 and 0.488 & -0.175 and 0.252 \\
\hline
\end{tabular}

\section{Conclusions}

As a result of this work, new co-crystals were discovered and characterized by DSC, FTIR and XRPD: (1:3) DAP:NA, (1:1) DAP:THEO, two polymorphic (1:2) DAP:THEO cocrystals, a (1:2:1) DAP:THEO:EtAc solvate and a (1:2) TMP:THEO co-crystal; the crystalline structures of the latter two were solved.

In Table 5, a summary of the results of the co-crystal screening outcomes is presented. This work demonstrated the possible use of the pharmacophore of dihydrofolate reductase inhibitors as a guide for co-crystal screening, recognizing some similar trends in the outcome of association in the solid state, and in the molecular aggregation in the co-crystals characterized by the same supramolecular synthons. Nevertheless, the co-crystal outcome for the API will always be more or less influenced by the remaining molecular fragments and the result of a balance of all interactions in the crystal lattice environment.

The comparison of the experimental co-crystallization outcome with the prediction of the virtual co-crystal screening with COSMOquick confirms the low propensity of DAP, TMP and PMA to co-crystallize with pyridinecarboxamides, with a successful outcome only observed for DAP + nicotinamide. Co-crystallization attempts with theophylline were well predicted; while using caffeine as co-former, they were not successful for DAP and TMP, contrarily to what was predicted by the in silico method. This shows that the method is useful as a preliminary guide to co-crystal screening, although it is limited by misrepresentation of complete conformational space, explicit hydrogen bonding, crystal packing and kinetic factors. 
Table 5. Summary of co-crystal screening results for DAP, TMP and PMA, with the co-formers PA, INA, NA, THEO and CAF.

\begin{tabular}{cccc}
\hline \multirow{2}{*}{ co-Former } & \multicolumn{3}{c}{ Target } \\
\cline { 2 - 4 } & DAP & TMP & PMA \\
\hline PA & $\mathbf{X}$ & $\mathbf{X}$ & $\mathbf{X}$ \\
INA & $\mathbf{X}$ & $\mathbf{X}$ & $\mathbf{X}$ \\
NA & $\checkmark$ & $\checkmark$ & $\sqrt{(27,28)}$ \\
THEO & $\checkmark$ & $\mathbf{X}$ & $\sqrt{(27)}$ \\
CAF & $\mathbf{X}$ & & \\
\hline
\end{tabular}

X-no co-crystal; $\sqrt{ }$-co-crystal formed.

Supplementary Materials: Figure S1: (Solid + liquid) binary phase diagrams of DAP + PA/INA; TMP + PA/INA/NA; PMA + PA/INA/NA; Figures S2-S10: DSC heating curves for binary mixtures $\mathrm{DAP}+\mathrm{PA} / \mathrm{INA} / \mathrm{NA}, \mathrm{TMP}+\mathrm{PA} / \mathrm{INA} / \mathrm{NA}, \mathrm{PMA}+\mathrm{PA} / \mathrm{INA} / \mathrm{NA}$; Figures S11-S18: FTIR of binary mixtures DAP + PA/INA, TMP + PA/INA/NA, PMA + PA/INA/NA; Figure S19: FTIR of binary mixtures DAP + NA; Figure S20: FTIR of DAP + THEO mixtures; Figure S21: TG curves of DAP + THEO, $\mathrm{xDAP}=0.33 \mathrm{NG}$, open and pierced pans; Figure S22: DSC heating curves of $\mathrm{xDAP}=0.33, \mathrm{LAG}$ and NG, submitted to different thermal treatments; Figure S23; XRPD of (1:1) DAP:THEO prepared by LAG and by NG; Figure S24: (Solid + liquid) binary phase diagram of DAP + CAF; FigureS25 and S26: DSC heating curves and FTIR of binary mixtures DAP + CAF; Figure S27: FTIR of binary mixtures TMP + THEO; Figure S28: (Solid + liquid) binary phase diagram of TMP + CAF; Figures S29 and S30: DSC heating curves and FTIR of binary mixtures TMP + CAF; Figure S31: Representation of hydrogen-bonded chains in theophylline, polymorph II; Figure S32: Comparison of XRPD LAG (1:2) TMP:THEO co-crystal, LAG co-crystal exposed to a saturated water atmosphere for 15 days and simulated from CCDC2109486; Table S1: melting temperature and enthalpy of the compounds used in the current work. CIF files with the single crystal X-ray diffraction structures of (1:2)TMP:THEO (17\% H2O), CCDC 2109486, and (1:2:1) DAP:THEO:EtAc, CCDC 2108308, are available from the Cambridge Crystallographic Data Center.

Author Contributions: J.A.B.: Methodology, investigation, draft writing and revision; M.T.S.R.: Supervision, methodology, draft writing and revision; R.A.E.C.: investigation and revision; A.O.L.É., investigation; T.M.R.M.: investigation and revision; M.R.S.: single crystal X-ray diffraction; J.C.: Conceptualization and revision; M.E.S.E.: Conceptualization, supervision, methodology, draft writing and revision. All authors have read and agreed to the published version of the manuscript.

Funding: This work is supported by Coimbra Chemistry Center (CQC) through the Fundação para a Ciência e a Tecnologia, FCT, Portugal, project UID/QUI/00313/2020. Thanks are due to UCQFarma for the use of XRPD and thermogravimetry equipment. J.A.B. and A.O.L.E. acknowledge Fundação para a Ciência e a Tecnologia (FCT) Portugal for financial support (UI/BD/150859/2021 and SFRH/BPD/115697/2016 grants, respectively).

Institutional Review Board Statement: Not applicable.

Informed Consent Statement: Not applicable.

Data Availability Statement: Data are available from the corresponding author upon reasonable request.

Conflicts of Interest: The authors declare no conflict of interest.

Sample Availability: Samples of the compounds are not available from the authors.

\section{References}

1. Then, R.L. History and future of antimicrobial diaminopyrimidines. J. Chemother. 1993, 5, 361-368. [CrossRef]

2. Anderson, A.C. Targeting DHFR in parasitic protozoa. Drug Discov. Today 2005, 10, 121-128. [CrossRef]

3. Rao, A.S.; Tapale, S.R. A study on dihydrofolate reductase and its inhibitors: A review. Int. J. Pharm. Sci. Res. 2013, 4, 2535-2547. 
4. Tropak, M.B.; Zhang, J.M.; Yonekawa, S.; Rigat, B.A.; Aulakh, V.S.; Smith, M.R.; Hwang, H.J.; Ciufolini, M.A.; Mahuran, D.J. Pyrimethamine Derivatives: Insight into Binding Mechanism and Improved Enhancement of Mutant beta-N-acetylhexosaminidase Activity. J. Med. Chem. 2015, 58, 4483-4493. [CrossRef] [PubMed]

5. Dunay, I.R.; Gajurel, K.; Dhakal, R.; Liesenfeld, O.; Montoya, J.G. Treatment of Toxoplasmosis: Historical Perspective, Animal Models, and Current Clinical Practice. Clin. Microbiol. Rev. 2018, 31, 33. [CrossRef]

6. He, J.; Qiao, W.L.; An, Q.; Yang, T.; Luo, Y.F. Dihydrofolate reductase inhibitors for use as antimicrobial agents. Eur. J. Med. Chem. 2020, 195, 112268. [CrossRef]

7. Hopper, A.T.; Brockman, A.; Wise, A.; Gould, J.; Barks, J.; Radke, J.B.; Sibley, L.D.; Zou, Y.M.; Thomas, S. Discovery of Selective Toxoplasma gondii Dihydrofolate Reductase Inhibitors for the Treatment of Toxoplasmosis. J. Med. Chem. 2019, 62, 1562-1576. [CrossRef]

8. Nelson, R.G.; Rosowsky, A. Dicyclic and tricyclic diaminopyrimidine derivatives as potent inhibitors of Cryptosporidium parvum dihydrofolate reductase: Structure-activity and structure-selectivity correlations. Antimicrob. Agents Chemother. 2001, 45, 3293-3303. [CrossRef]

9. Zhou, Y.Q.; Guo, T.L.; Li, X.T.; Dong, Y.; Galatsis, P.; Johnson, D.S.; Pan, Z.Y. Discovery of selective 2,4-diaminopyrimidine-based photoaffinity probes for glyoxalase I. MedChem Comm 2014, 5, 352-357. [CrossRef]

10. Raimondi, M.V.; Randazzo, O.; La Franca, M.; Barone, G.; Vignoni, E.; Rossi, D.; Collina, S. DHFR Inhibitors: Reading the Past for Discovering Novel Anticancer Agents. Molecules 2019, 24, 1140. [CrossRef]

11. Nammalwar, B.; Bourne, C.R.; Wakeham, N.; Bourne, P.C.; Barrow, E.W.; Muddala, N.P.; Bunce, R.A.; Berlin, K.D.; Barrow, W.W. Modified 2,4-diaminopyrimidine-based dihydrofolate reductase inhibitors as potential drug scaffolds against Bacillus anthracis. Bioorg. Med. Chem. 2015, 23, 203-211. [CrossRef]

12. Duggirala, N.K.; Perry, M.L.; Almarsson, Ö.; Zaworotko, M.J. Pharmaceutical cocrystals: Along the path to improved medicines. Chem. Commun. 2016, 52, 640-655. [CrossRef] [PubMed]

13. Grothe, E.; Meekes, H.; Vlieg, E.; ter Horst, J.H.; de Gelder, R. Solvates, Salts, and Cocrystals: A Proposal for a Feasible Classification System. Cryst. Growth Des. 2016, 16, 3237-3243. [CrossRef]

14. Desiraju, G.R. Supramolecular synthons in crystal engineering-A new organic synthesis. Angew. Chem. Int. Ed. 1995, 34, 2311-2327. [CrossRef]

15. Weyna, D.R.; Shattock, T.; Vishweshwar, P.; Zaworotko, M.J. Synthesis and Structural Characterization of Cocrystals and Pharmaceutical Cocrystals: Mechanochemistry vs Slow Evaporation from Solution. Cryst. Growth Des. 2009, 9, 1106-1123. [CrossRef]

16. Zheng, Q.X.; Unruh, D.K.; Hutchins, K.M. Cocrystallization of Trimethoprim and Solubility Enhancement via Salt Formation. Cryst. Growth Des. 2021, 21, 1507-1517. [CrossRef]

17. Maity, D.K.; Paul, R.K.; Desiraju, G.R. Drug-Drug Binary Solids of Nitrofurantoin and Trimethoprim: Crystal Engineering and Pharmaceutical Properties. Mol. Pharm. 2020, 17, 4435-4442. [CrossRef] [PubMed]

18. Bhattacharya, B.; Das, S.; Lal, G.; Soni, S.R.; Ghosh, A.; Reddy, C.M.; Ghosh, S. Screening, crystal structures and solubility studies of a series of multidrug salt hydrates and cocrystals of fenamic acids with trimethoprim and sulfamethazine. J. Mol. Struct. 2020, 1199, 127028. [CrossRef]

19. Darious, R.S.; Muthiah, P.T.; Perdih, F. Supramolecular hydrogen-bonding patterns in salts of the antifolate drugs trimethoprim and pyrimethamine. Acta Crystallogr. C Struct. 2018, 74, 487-503. [CrossRef]

20. Giuseppetti, G.; Tadini, C.; Bettinetti, G.P. 1/1-Molecular-complex of trimethoprim and sulfametrole. Acta Crystallogr. Sect. C Cryst. Struct. Commun. 1994, 50, 1289-1291. [CrossRef]

21. Muthiah, P.T.; Hemamalini, M.; Bocelli, G.; Cantoni, A. Hydrogen-bonded supramolecular motifs in crystal structures of trimethoprim barbiturate monohydrate (I) and 2-amino-4,6-dimethylpyrimidinium barbiturate trihydrate (II). Struct. Chem. 2007, 18, 171-180. [CrossRef]

22. Raj, S.B.; Sethuraman, V.; Francis, S.; Hemamalini, M.; Muthiah, P.T.; Bocelli, G.; Cantoni, A.; Rychlewska, U.; Warzajtis, B. Supramolecular organization via hydrogen bonding in trimethoprim sulfonate salts. CrystEngComm 2003, 15, 70-76.

23. Sardone, N.; Bettinetti, G.; Sorrenti, M. Trimethoprim-sulfadimidine 1:2 molecular complex monohydrate. Acta Crystallogr. Sect. C Cryst. Struct. Commun. 1997, 53, 1295-1299. [CrossRef]

24. Ton, Q.C.; Egert, E. Cocrystals of the antibiotic trimethoprim with glutarimide and 3,3-dimethylglutarimide held together by three hydrogen bonds. Acta Crystallogr. Sect. C Cryst. Struct. Commun. 2015, 71, 212-228. [CrossRef] [PubMed]

25. Tilborg, A.; Carletta, A.; Wouters, J. Structural and energy insights on solid-state complexes with trimethoprim: A combined theoretical and experimental investigation. Acta Crystallogr. B Struct. Sci. Cryst. Eng. Mater. 2015, 71, 406-415. [CrossRef]

26. Stanley, N.; Sethuraman, V.; Muthiah, P.T.; Luger, P.; Weber, M. Crystal engineering of organic salts: Hydrogen-bonded supramolecular motifs in pyrimethamine hydrogen glutarate and pyrimethamine formate. Cryst. Growth Des. 2002, 2, 631-635. [CrossRef]

27. Baptista, J.A.; Castro, R.A.E.; Rosado, M.T.S.; Maria, T.M.R.; Silva, M.R.; Canotilho, J.; Eusébio, M.E.S. Polymorphic Cocrystals of the Antimalarial Drug Pyrimethamine: Two Case Studies. Cryst. Growth Des. 2021, 21, 3699-3713. [CrossRef]

28. Delori, A.; Galek, P.T.A.; Pidcock, E.; Patni, M.; Jones, W. Knowledge-based hydrogen bond prediction and the synthesis of salts and cocrystals of the anti-malarial drug pyrimethamine with various drug and GRAS molecules. CrystEngComm 2013, 15, 2916-2928. [CrossRef] 
29. Balasubramani, K.; Muthiah, P.T.; Bocelli, G.; Cantoni, A. Pyrimethaminium nicotinate monohydrate. Acta Crystallogr. Sect. E 2007, 63, O4452-O4683. [CrossRef]

30. Balasubramani, K.; Muthiah, P.T.; Rychlewska, U.; Plutecka, A. Hydrogen-bonding patterns in pyrimethaminium dinitrate. Acta Crystallogr. Sect. C Cryst. Struct. 2005, 61, O586-O588. [CrossRef]

31. Devi, P.; Muthiah, P.T.; Rychlewska, U.; Plutecka, A. Hydrogen-bonding patterns in pyrimethaminium 3-chlorobenzoate. Acta Crystallogr. Sect. E 2006, 62, O3704-O3706. [CrossRef]

32. Hemamalini, M.; Muthiah, P.T.; Sridhar, B.; Rajaram, R.K. Pyrimethaminium sulfosalicylate monohydrate. Acta Crystallogr. Sect. E. 2005, 61, O1480-O1482. [CrossRef]

33. Sethuraman, V.; Stanley, N.; Muthiah, P.T.; Sheldrick, W.S.; Winter, M.; Luger, P.; Weber, M. Isomorphism and crystal engineering: Organic ionic ladders formed by supramolecular motifs in pyrimethamine salts. Cryst. Growth Des. 2003, 3, 823-828. [CrossRef]

34. Chen, J.Y.; Wang, X.Y.; Hong, M.H.; Yi, D.X.; Qi, M.H.; Ren, G.B. Structure properties of scoparone: Polymorphs and cocrystals. J. Mol. Struct. 2019, 1191, 323-336. [CrossRef]

35. Hutzler, W.M.; Bolte, M. Sulfur as hydrogen-bond acceptor in cocrystals of 2-thio-modified thymine. Acta Crystallogr. Sect. C 2018, 74, 21-30. [CrossRef]

36. Hutzler, W.M.; Egert, E.; Bolte, M. 6-Propyl-2-thiouracil versus 6-methoxymethyl-2-thiouracil: Enhancing the hydrogen-bonded synthon motif by replacement of a methylene group with an O atom. Acta Crystallogr. Sect. C 2016, 72, 634-646. [CrossRef] [PubMed]

37. Hutzler, W.M.; Egert, E.; Bolte, M. One barbiturate and two solvated thiobarbiturates containing the triply hydrogen-bonded ADA/DAD synthon, plus one ansolvate and three solvates of their coformer 2,4-diaminopyrimidine. Acta Crystallogr. Sect. C 2016, 72, 705-715. [CrossRef]

38. Matulkova, I.; Mathauserova, J.; Cisarova, I.; Nemec, I.; Fabry, J. The study of crystal structures and vibrational spectra of inorganic salts of 2,4-diaminopyrimidine. J. Mol. Struct. 2016, 1103, 82-93. [CrossRef]

39. Hutzler, W.M.; Egert, E. Cocrystals of 6-methyl-2-thiouracil: Presence of the acceptor-donor-acceptor/donor-acceptor-donor synthon. Acta Crystallogr. Sect. C 2015, 71, 229-238. [CrossRef]

40. Abramov, Y.A.; Loschen, C.; Klamt, A. Rational coformer or solvent selection for pharmaceutical cocrystallization or desolvation. J. Pharm. Sci. 2012, 101, 3687-3697. [CrossRef]

41. Loschen, C.; Klamt, A. Solubility prediction, solvate and cocrystal screening as tools for rational crystal engineering. J. Pharm. Pharmacol. 2015, 67, 803-811. [CrossRef] [PubMed]

42. Prigogine, I.; Defay, R. Chemical Thermodynamics; Longmans, Green and Co: Glasgow, UK, 1954.

43. Hohne, G.W.H.; Cammenga, H.K.; Eysel, W.; Gmelin, E.; Hemminger, W. The temperature calibration of scanning calorimeters. Thermochim. Acta 1990, 160, 1-12. [CrossRef]

44. Gallis, H.E.; vanMiltenburg, J.C. Mixtures of d- and l-carvone 2. Adiabatic calorimetry on the equimolar mixture. Thermochim. Acta 1996, 274, 223-230. [CrossRef]

45. Chan, H.C.S.; Woollam, G.R.; Wagner, T.; Schmidt, M.U.; Lewis, R.A. Can picolinamide be a promising cocrystal former? CrystEngComm 2014, 16, 4365-4368. [CrossRef]

46. Habgood, M.; Deij, M.A.; Mazurek, J.; Price, S.L.; ter Horst, J.H. Carbamazepine Co-crystallization with Pyridine Carboxamides: Rationalization by Complementary Phase Diagrams and Crystal Energy Landscapes. Cryst. Growth Des. 2010, 10, 903-912. [CrossRef]

47. Desiraju, G.R.; Steiner, T. The Weak Hydrogen Bond, IUCr Monographs on Crystallography; Oxford University Press: Oxford, UK, 2001; Volume 9.

48. Spackman, M.A.; McKinnon, J.J. Fingerprinting intermolecular interactions in molecular crystals. CrystEngComm 2002, 4, 378-392. [CrossRef]

49. Ebisuzaki, Y.; Boyle, P.D.; Smith, J.A. Methylxanthines 1. Anhydrous theophylline. Acta Crystallogr. Sect. C 1997, 53, 777-779. [CrossRef]

50. Raauf, A.M.R.; Al-Smaism, R.F.; Thejeel, K.A.; Rasheed, H.A.M. Synthesis, characterization and antimicrobial study via new heterocyclic derivatives of trimethoprim. Nat. Prod. Res. 2019, 33, 1277-1283. [CrossRef]

51. Sethuraman, V.; Muthiah, P.T. Hydrogen-bonded supramolecular ribbons in the antifolate drug pyrimethamine. Acta Crystallogr. Sect. E 2002, 58, o817-o819. [CrossRef]

52. Rauf, K. (Department of Chemistry, Quaid-i-Azam University, Islamabad Pakistan); Bolte, M. (Institut für Anorganische Chemie, J.W. Goethe-Universität Frankfurt Germany). 2,4-Diamino-5-(3,4,5-trimethoxybenzyl)pyrimidine. CSD Communication (Private Communication), 2006. [CrossRef]

53. Miwa, Y.; Mizuno, T.; Tsuchida, K.; Taga, T.; Iwata, Y. Experimental charge density and electrostatic potential in nicotinamide. Acta Crystallogr. Sect. B 1999, 55, 78-84. [CrossRef]

54. Takano, T.; Sasada, Y.; Kakudo, M. Crystal and molecular structure of picolinamide. Acta Crystallogr. 1966, 21, 514-522. [CrossRef] [PubMed]

55. Evora, A.O.L.; Castro, R.A.E.; Maria, T.M.R.; Rosado, M.T.S.; Silva, M.R.; Canotilho, J.; Eusébio, M.E.S. Resolved structures of two picolinamide polymorphs. Investigation of the dimorphic system behaviour under conditions relevant to co-crystal synthesis. CrystEngComm 2012, 14, 8649-8657. 
56. Aakeroy, C.B.; Beatty, A.M.; Helfrich, B.A.; Nieuwenhuyzen, M. Do polymorphic compounds make good cocrystallizing agents? A structural case study that demonstrates the importance of synthon flexibility. Cryst. Growth Des. 2003, 3, 159-165.

57. Lehmann, C.W.; Stowasser, F. The crystal structure of anhydrous beta-caffeine as determined from X-ray powder-diffraction data. Chem. Eur. J. 2007, 13, 2908-2911. [CrossRef] [PubMed]

58. Hornig, M.; Klamt, A. COSMOfrag: A novel tool for high-throughput ADME property prediction and similarity screening based on quantum chemistry. J. Chem. Inf. Comput. Sci. 2005, 45, 1169-1177. [CrossRef]

59. Evora, A.O.L.; Castro, R.A.E.; Maria, T.M.R.; Silva, M.R.; Canotilho, J.; Eusébio, M.E.S. Lamotrigine: Design and synthesis of new multicomponent solid forms. Eur. J. Pharm. Sci. 2019, 129, 148-162. [CrossRef]

60. Choquesillo-Lazarte, D.; Garcia-Ruiz, J.M. Poly(ethylene) oxide for small-molecule crystal growth in gelled organic solvents. J. Appl. Crystallogr. 2011, 44, 172-176. [CrossRef]

61. Sheldrick, G.M. SHELXS-97, Program for Solution of Crystal Structures; University of Göttingen: Göttingen, Germany, 1997.

62. Sheldrick, G.M. SHELXL-97, Program for Refinement of Crystal Structures; University of Göttingen: Göttingen, Germany, 1997.

63. McKinnon, J.J.; Jayatilaka, D.; Spackman, M.A. Towards quantitative analysis of intermolecular interactions with Hirshfeld surfaces. Chem. Commun. 2007, 37, 3814-3816. [CrossRef] [PubMed]

64. Spackman, M.A.; Jayatilaka, D. Hirshfeld surface analysis. CrystEngComm 2009, 11, 19-32. [CrossRef] 